\title{
A Study Identifying Biological Evolution-Related Misconceptions Held by Prebiology High School Students
}

\author{
Tony B. Yates ${ }^{1}$, Edmund A. Marek ${ }^{2}$ \\ ${ }^{1}$ Department of Natural Science, Oklahoma Baptist University Shawnee, Shawnee, USA \\ ${ }^{2}$ Department of Instructional Leadership and Academic Curriculum, University of Oklahoma, Norman, USA \\ Email: tony.yates@okbu.edu, eamarek@ou.edu
}

Received 23 March 2015; accepted 24 May 2015; published 27 May 2015

Copyright (C) 2015 by authors and Scientific Research Publishing Inc.

This work is licensed under the Creative Commons Attribution International License (CC BY).

http://creativecommons.org/licenses/by/4.0/

(c) (i) Open Access

\section{Abstract}

Students bring a diverse array of ideas about natural events to their science classes, and many of these ideas are often at variance with the scientifically accepted views. Numerous studies have identified multiple biological evolution-related misconceptions held by select groups of students. Collectively, these studies repeatedly indicate that students with varying educational backgrounds have difficulties accurately understanding the concepts of evolution. Because scientific literacy in the field of biology necessitates a basic understanding of evolution concepts and theory, students' possession of biological evolution-related misconceptions is problematic. The focus of this study was to identify the types and prevalence of such misconceptions within a state's public high schools' prebiology students and to correlate those findings with demographic variables. Some 993 students enrolled in their initial high school biology course during the 2010-2011 academic years in one of 42 Oklahoma public high schools served as this study's unit of analysis. The Biological Evolution Literacy Survey which presents 23 biological misconception statements grouped into five categories, served as the research tool for identifying students' misconceptions, calculating conception index scores, and collecting demographic data. Multiple statistical analyses were performed to identify statistically significant $(p<0.05)$ relationships between variables related to students' number and types of misconceptions. Analysis revealed that participants possess a mean 43.9\% rate of understanding of those biological evolution concepts presented in the BEL Survey combined with a $39.1 \%$ mean misconception rate. A statistically significant difference in participants' BEL Survey mean index scores when related to biological evolution knowledge self-rating was also disclosed. Strategies for identifying and eliminating students' misconceptions are offered. Misconceptions of biological evolution were prevalent within this student population and the findings corroborate the literature that reports a strikingly high prevalence of biological evolution-related misconceptions in students at all levels, from elementary pupils to university science 
majors.

Keywords

Evolution, Misconceptions, Oklahoma, Prebiology, Student

\section{Introduction}

Students bring a diverse array of ideas about natural phenomena to their science classes and many of these ideas are often at variance with the scientifically accepted views (Kampourakis \& Zogza, 2007). Numerous studies conducted in recent decades identify multiple biological evolution-related misconceptions held by select groups of students. These groups include: secondary students (Beardsley, 2004; Bizzo, 1994; Clough \& Wood-Robinson, 1985; Creedy, 1993; Deadman \& Kelly, 1978; Demastes et al., 1995; Evans, 2000; Geraedts \& Boersma, 2006; Halldén, 1988; Jiménez-Aleixandre, 1992; Jungwirth, 1975; Kampourakis \& Zogza, 2007, 2008, 2009; Lawson \& Thompson, 1988; Palmer, 1999; Pedersen \& Halldén, 1992; Prinou et al., 2008; Settlage, 1994; Shtulman, 2006; Spindler \& Doherty, 2009; Tamir \& Zohar, 1991); first year undergraduate students (Brumby, 1979; Jensen \& Finley, 1995; Nehm \& Reilly, 2007; Sundberg \& Dini, 1993); second year undergraduate students (Jiménez-Aleixandre \& Fernández-Pérez, 1987) collective undergraduate students (Anderson et al., 2002; Bishop \& Anderson, 1990; Brem et al., 2002; Chinsamy \& Plagányi, 2007; Demastes et al., 1995; Ferrari \& Chi, 1998; Hokayem \& BouJaoude, 2008; Jensen \& Finley, 1996; Meir et al., 2007; Paz-y-Mińo \& Espinosa, 2009; Robbins \& Roy, 2007; Shtulman, 2006; Wescott \& Cunningham, 2005); medical students (Brumby, 1984); and physics doctoral students (Chan, 1998). Collectively, these studies repeatedly indicate that students of all ages and with varying educational backgrounds have difficulties accurately understanding the concepts constituting evolution (Stern \& Ben-Akiva, 2007).

More than a century of efforts in evolution education have revealed a diverse array of tenacious and pervasive misconceptions (see Nehm \& Schonfeld, 2007) ranging from minor misunderstandings to complete theory rejection (Alters \& Alters, 2001; Dagher \& BouJaoude, 2005; Evans, 2001; Mazur, 2004; McComas, 2006; Sadler, 2005). Repeatedly, studies have shown that students often lack (or reject) a naturalistic scientific worldview (Evans et al., 2010); fail to adopt evolution as a conceptual organizer for the life sciences (Nehm et al., 2009); and utilize faulty evolutionary reasoning patterns (teleology, essentialism, and intentionality) characteristic of young children (Sinatra et al., 2008). These factors contribute to student acquisition and formation of biological evolution-related misconceptions. Common biological evolution misconceptions seem to have a life of their own with some of the most pervasive ones having persisted for decades despite all efforts to correct them (Mead \&Scott, 2010a; Mead \& Scott, 2010b; Petto \& Mead, 2008). The problem of student acquisition and adherence to these misconceptions lies in the fact that scientific literacy in the field of biology necessitates understanding the theory of evolution (Dobzhansky, 1973), as emphasized by Bishop and Anderson (1990): "For the science of biology, the theory of evolution provides a unifying framework within which many diverse facts are integrated and explained. For this reason, an understanding of modern biology is incomplete without an understanding of evolution" (p. 415).

To assess public high school prebiology students' knowledge of biological evolution, we surveyed 993 students from across a southern state (U.S. Census Bureau, 2010). The specific purpose of this study was to identify the types and prevalence of biological evolution-related misconceptions held by the these students and to correlate these data with known variables including gender, grade level, ethnicity, self-rating of biological evolution knowledge (see Table 1) and students' public high schools' urban-centric and average daily membership (ADM) classifications (see Table 2) Such a diagnosis of misconceptions is an initial, crucial step in the process of conceptual change (Duit \& Treagust, 2003). Although we do not claim that the findings of this study undertaken in a single southern state are applicable nationwide, results obtained do contribute to the biological evolution misconception literature and may be compared to similar studies which differ geographically and/or temporally. Additionally, data acquired from this study will be analyzed in a subsequent study in order to identify any changes that may have occurred in the types, prevalence, and correlational relationships of those misconceptions identified as being held by students in this present study following completion of their initial high school biology course. 
Table 1. Student profile.

\begin{tabular}{|c|c|c|c|c|}
\hline Demographic Variable & Variables & $n$ & $\%^{*}$ & BEL-MIS \\
\hline \multirow[t]{3}{*}{ Gender } & Female & 512 & 51.6 & 69.94 \\
\hline & Male & 479 & 48.2 & 70.77 \\
\hline & No response & 2 & 0.2 & - \\
\hline \multirow[t]{5}{*}{ Grade } & Freshman & 237 & 23.9 & 70.29 \\
\hline & Sophomore & 716 & 72.1 & 70.26 \\
\hline & Junior & 27 & 2.7 & 73.04 \\
\hline & Senior & 8 & 0.8 & 71.50 \\
\hline & No response & 5 & 0.5 & - \\
\hline \multirow[t]{6}{*}{ Ethnicity } & American Indian or Alaska Native & 157 & 15.8 & 70.54 \\
\hline & Asian or Pacific Islander & 18 & 1.8 & 71.94 \\
\hline & Black, non-Hispanic & 33 & 3.3 & 69.76 \\
\hline & Hispanic & 56 & 5.6 & 69.12 \\
\hline & White, non-Hispanic & 713 & 71.8 & 70.35 \\
\hline & No response & 16 & 1.6 & - \\
\hline \multirow[t]{6}{*}{ Knowledge self-rating } & Excellent & 36 & 3.6 & 70.08 \\
\hline & Good & 146 & 14.7 & $72.55^{\mathrm{ab}}$ \\
\hline & Average & 433 & 43.6 & 70.56 \\
\hline & Fair & 224 & 22.6 & $69.49^{\mathrm{a}}$ \\
\hline & Poor & 143 & 14.4 & $68.92^{\mathrm{b}}$ \\
\hline & No response & 11 & 1.1 & - \\
\hline \multirow[t]{5}{*}{ Average daily membership } & $4451.85-485.57$ & 284 & 28.6 & 70.57 \\
\hline & $482.10-242.95$ & 233 & 23.5 & 69.70 \\
\hline & $242.30-134.10$ & 260 & 26.2 & 69.96 \\
\hline & $132.10-78.11$ & 126 & 12.7 & 71.72 \\
\hline & $77.73-14.85$ & 90 & 9.1 & 70.44 \\
\hline \multirow[t]{4}{*}{ Urban centric classification } & City & 25 & 2.5 & 69.92 \\
\hline & Suburban & 69 & 7.0 & 71.56 \\
\hline & Town & 407 & 41.0 & 70.21 \\
\hline & Rural & 492 & 49.5 & 70.30 \\
\hline
\end{tabular}

Note: BEL-MIS = BEL Survey mean index score. Maximum BEL-MIS is 115. Those BEL-MIS possessing the same subscript are significantly different at $p<0.05$. ${ }^{*}$ Percent may not total $100.0 \%$ due to rounding. 
Table 2. Public high school profile.

\begin{tabular}{|c|c|c|c|}
\hline \multirow{2}{*}{ Demographic variable } & \multirow{2}{*}{ Variable range } & \multicolumn{2}{|c|}{ Percentage of High Schools } \\
\hline & & Participant HS $(N=42)$ & Study area HS $(N=474)$ \\
\hline \multirow[t]{5}{*}{ Average daily membership ${ }^{* a}$} & $4461.85-485.57$ & 26.2 & 20.0 \\
\hline & $482.10-242.95$ & 21.4 & 20.0 \\
\hline & $242.30-134.10$ & 21.4 & 20.0 \\
\hline & $132.10-78.11$ & 14.3 & 20.0 \\
\hline & $77.73-14.85$ & 16.7 & 20.0 \\
\hline \multirow[t]{4}{*}{ Urban-centric classification ${ }^{* * b}$} & City & 2.4 & 7.2 \\
\hline & Suburban & 7.1 & 5.7 \\
\hline & Town & 26.2 & 17.7 \\
\hline & Rural & 64.3 & 69.4 \\
\hline
\end{tabular}

Note: $H S$ = high school. Participant high schools contain study participants whereas study area high schools are the total number of high schools within the study area. ${ }^{\mathrm{a}}$ Average daily membership (ADM) is the aggregate membership of a school during a reporting period (normally a school year)

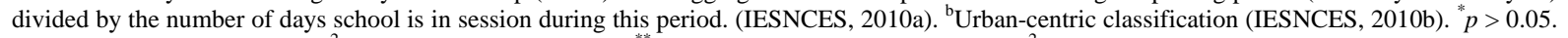
Difference is not significant. $\mathrm{X}^{2}(4, N=42)=4.29, p=0.37 .{ }^{* *} p<0.05$. Difference is significant. $\mathrm{X}^{2}(3, N=42)=8.0, p=0.046$.

While the aforementioned multiple studies have addressed the issue of biological evolution-related misconceptions in various student populations, this study is the first to address this issue in a sample population of Oklahoma high school prebiology students by means of the Biological Evolution Literacy Survey (BEL Survey).

\section{Method}

\subsection{Participants and Biology Course}

Participants included 993 public high school first-year biology students (479 males, 512 females, 2 gender unknown) enrolled during the 2010-2011 academic year in one of 42 of the 474 public high schools located within Oklahoma (Oklahoma State Department of Education [OSDE], 2009a) which served as the study region. For the purposes of this study, a high school is defined as a secondary school offering any combination of grades 9 through 12. All participants were first-time enrollees in a Biology I course at the beginning of the fall 2010 semester. Biology I is a core curriculum course that is required for high school graduation and is typically taken by freshmen and sophomore students (OSDE, 2009b). Biology I investigates content, concepts, and principles of major themes in the biological sciences (OSDE, 2009c) and serves as the prerequisite course for subsequent high school biology courses students may take (OSDE, 2009b).

\subsection{Instrumentation}

To identify student participants' knowledge structure and misconceptions of biological evolution, an instrument was developed called the Biological Evolution Literacy Survey (BEL Survey; Yates \& Marek, 2011: pp. 32-33). Initially, student participants' Biology I teachers were contacted via a recruitment letter. Teachers who volunteered for the study $(N=45)$ administered the BEL Survey to students in one section of their Biology I course within the initial week following the beginning of classes in the fall 2010 semester. Teachers were instructed to administer the BEL Survey to students in only one section of the course in order to reduce peer influence on students' opinions concerning the survey statements. Administering the survey as early as possible in the course was done to minimize students' exposure to biological evolution concepts taught in their initial high school biology course and to reduce teacher influence on students' opinions concerning the BEL Survey statements.

With permission, the BEL Survey was modeled after Cunningham and Wescott's 2009 survey which, in turn, was adapted from Almquist and Cronin (1988) with additions from Wilson (2001), and Bishop and Anderson (1986, 1990). The initial survey produced by Almquist and Cronin attempted to identify college and university students' basic knowledge concerning the processes of evolution and their opinions on issues pertaining to 
science and religion. The purpose of Cunningham and Wescott's 2009 study was to identify the common misconceptions held by undergraduate students and to explain the reasoning behind those misconceptions. In addition, Cunningham and Wescott were interested in assessing how students' opinions and understanding of evolutionary theory may have changed in the interim since the 1988 Almquist and Cronin study.

The BEL Survey is composed of two sections to be completed in anonymity. The first section requested demographic data which included gender, grade level, ethnicity, self-rating of evolution knowledge, and indication as to whether the student had previously enrolled in a Biology I course. Any student whose survey indicated previous enrollment in a Biology I course was omitted from the study. The second section of the BEL Survey asked student participants to respond to whether they strongly agree, somewhat agree, strongly disagree, somewhat disagree, or have no opinion ("undecided/or never heard of it") on 23 statements related to biological evolution-related misconceptions. Two methods of scoring responses were used during data analysis. First, the responses "strongly agree" and "somewhat agree" were combined, indicating participant agreement with the statement. Likewise, the responses "strongly disagree" and "somewhat disagree" were combined, indicating participant disagreement with the statement. Second, by means of Likert scaling of responses, a biological evolution misconception scoring index was created with answers to statements indicative of a low acceptance of an evolution concept (high acceptance of the associated misconception) receiving low scores and answers to statements indicative of a high acceptance of an evolution concept (nonacceptance of misconception) receiving high scores. For statements in which agreement indicated nonacceptance of the associated misconception (statements 2, 4, 8, 10, 11, 14, 15, 18, 20, 23), index scoring was as follows: (a) strongly agree, score of 5; (b) somewhat agree, 4; (c) undecided/ never heard of it, 3; (d) somewhat disagree, 2; (e) strongly disagree, 1; and (f) no response, 0 . For statements in which agreement indicated a high acceptance of the associated misconception (statements 1, 3, 5, 6, 7, 9, 12, 13, 16, 17, 19, 21, 22) index scoring was as follows: (a) strongly agree, 1; (b) somewhat agree, 2; (c) undecided/never heard of it, 3; (d) somewhat disagree, 4; (e) strongly disagree, 5; and (f) no response, 0 . The possible range of BEL Survey index scores was 0 to 115 with a score of 115 representing the highest level of understanding coupled with a lack of associated misconceptions whereas lower indices represented lower levels of understanding combined with higher levels of biological evolution-related misconceptions. In addition, a count of the number of misconceptions revealed by responses to the statements was conducted.

Cunningham and Wescott's (2009) survey instrument on which the BEL Survey is modeled contained 24 statements classified into four categories: (a) evolutionary theory, (b) scientific facts, (c) process of evolution, and (d) language of science. For the present study, Cunningham and Wescott's four-category classification was modified into five categories of biological evolution-related misconceptions that are commonly employed in the literature (e.g., Alters \& Alters, 2001; Bishop \& Anderson, 1990; Greene, 1990; Gregory, 2009; Jensen \& Finley, 1996; Wandersee et al., 1994; Wescott \& Cunningham, 2005; Wilson, 2001). These misconception categories include: (a) science, scientific methodology and terminology (SSMT); (b) intentionality of evolution (IE); (c) nature of evolution (NE); (d) mechanisms of evolution (ME); and (e) evidence supporting evolution (ESE). While five biological evolution-related misconception statements were identified or developed for each of the SSMT, IE, and ME categories, four such statements were identified or developed for each of the NE and ESE categories. Of the BEL Survey's 23 statements (see Table 3), two statements (11 and 16) were taken directly from Cunningham and Wescott's survey; eight were adapted from Cunningham and Wescott's survey $(1,6,7,9$, $15,17,20,22)$; and, the remaining 13 statements $(2,3,4,5,8,10,12,13,14,18,19,21,23)$ were developed through an extensive search of biological evolution misconception literature.

\section{Results and Discussion}

Table 1 presents the participant profile. Approximately 52\% percent of study participants were female $(n=512)$ and $48 \%$ male $(n=479)$. The majority of students were sophomores $(72.1 \%, n=716)$ with only a combined $3.5 \%$ $(n=35)$ being either juniors or seniors. Although $71.8 \%(n=713)$ of participants were white, non-Hispanic, Oklahoma's rich ethnic diversity was revealed with $15.8 \%(n=157)$ of participants claiming American Indian or Alaska Native descent, while 5.6\% $(n=56)$ were Hispanic. When asked to rate their knowledge of biological evolution prior to instruction in the Biology I course, $80.6 \%(n=800)$ indicated an average or less than average knowledge whereas a combined $18.3 \%(n=182)$ claimed either a good or excellent knowledge of biological evolutionary concepts. Student participants were fairly evenly split between public high schools possessing an ADM greater than $242.3(52.1 \%, n=517)$ and those high schools with an ADM equal to or less than 242.3 
Table 3. BEL survey statement percent student response.

\begin{tabular}{|c|c|c|c|c|c|c|c|c|}
\hline \multirow[t]{2}{*}{ \# } & \multirow[t]{2}{*}{ Category } & \multirow[t]{2}{*}{ Statement } & \multicolumn{6}{|c|}{ Student \% Response* } \\
\hline & & & 1 & 2 & 3 & 4 & 5 & 6 \\
\hline 1 & SSMT1 & $\begin{array}{l}\text { A scientific theory that explains a natural phenomenon can be } \\
\text { classified as a "best guess" or "hunch"a }\end{array}$ & 12.9 & 37.1 & 21.3 & 12.7 & 15.7 & 0.3 \\
\hline 2 & SSMT2 & $\begin{array}{l}\text { The scientific methods used to determine the age of fossils and } \\
\text { the earth are reliable. }\end{array}$ & 22.6 & 50.7 & 13.5 & 7.7 & 5.4 & 0.2 \\
\hline 3 & SSMT3 & $\begin{array}{l}\text { According to the second law of thermodynamics, complex life } \\
\text { forms cannot evolve from simpler life forms. }\end{array}$ & 9.4 & 12.0 & 19.5 & 16.3 & 41.9 & 0.9 \\
\hline 4 & SSMT4 & The earth is old enough for evolution to have occurred. & 27.9 & 28.9 & 12.5 & 19.2 & 10.9 & 0.6 \\
\hline 5 & SSMT5 & $\begin{array}{l}\text { Evolution cannot be considered a reliable explanation because } \\
\text { evolution is only a theory. }\end{array}$ & 29.8 & 25.0 & 21.3 & 12.9 & 10.7 & 0.3 \\
\hline 6 & IE1 & Evolution always results in improvement. ${ }^{a}$ & 6.7 & 23.3 & 28.7 & 25.4 & 14.3 & 1.6 \\
\hline 7 & IE2 & Members of a species evolve because of an inner need to evolve. ${ }^{a}$ & 10.3 & 28.1 & 22.3 & 17.8 & 21.0 & 0.5 \\
\hline 8 & IE3 & $\begin{array}{l}\text { Traits acquired during the lifetime of an organism—such as large muscles } \\
\text { produced by body building - will not be passed along to offspring. }\end{array}$ & 30.5 & 25.4 & 20.4 & 15.2 & 8.1 & 0.4 \\
\hline 9 & IE4 & $\begin{array}{l}\text { If webbed feet are being selected for, all individuals in the next } \\
\text { generation will have more webbing on their feet than do individuals } \\
\text { in their parents' generation. }{ }^{a}\end{array}$ & 10.2 & 30.1 & 21.9 & 12.5 & 24.5 & 0.9 \\
\hline 10 & IE5 & Evolution cannot cause an organism's traits to change within its lifetime. & 14.9 & 22.2 & 26.4 & 16.8 & 18.7 & 1.0 \\
\hline 11 & NE1 & New traits within a population appear at random. ${ }^{\mathrm{b}}$ & 9.4 & 31.8 & 26.1 & 15.5 & 16.5 & 0.7 \\
\hline 12 & NE2 & Individual organisms adapt to their environments. & 47.8 & 32.3 & 9.0 & 4.4 & 5.4 & 1.0 \\
\hline 13 & NE3 & Evolution is a totally random process. & 9.7 & 16.2 & 25.7 & 25.8 & 22.5 & 0.2 \\
\hline 14 & NE4 & The environment determines which traits are best suited for survival. & 26.1 & 33.7 & 16.5 & 11.0 & 11.9 & 0.8 \\
\hline 15 & ME1 & $\begin{array}{l}\text { Variation among individuals within a species is important for } \\
\text { evolution to occur. }^{\text {a }}\end{array}$ & 10.5 & 29.6 & 19.7 & 9.0 & 30.9 & 0.3 \\
\hline 16 & ME2 & "Survival of the fittest" means basically that "only the strong survive.”b & 35.6 & 26.9 & 17.3 & 13.6 & 6.3 & 0.2 \\
\hline 17 & ME3 & The size of the population has no effect on the evolution of a species ${ }^{a}$ & 10.8 & 19.3 & 31.9 & 23.0 & 14.8 & 0.2 \\
\hline 18 & ME4 & Complex structures such as the eye could have been formed by evolution. & 11.6 & 25.0 & 18.1 & 26.9 & 17.9 & 0.5 \\
\hline 19 & ME5 & Only beneficial traits are passed on from parent to offspring. & 8.8 & 21.8 & 25.6 & 33.5 & 9.3 & 1.0 \\
\hline 20 & ESE1 & $\begin{array}{l}\text { There exists a large amount of evidence supporting the theory of } \\
\text { evolution. }{ }^{\text {a }}\end{array}$ & 12.9 & 23.2 & 20.0 & 23.9 & 19.2 & 0.8 \\
\hline 21 & ESE2 & $\begin{array}{l}\text { According to the theory of evolution, humans evolved from monkeys, } \\
\text { gorillas, or apes. }\end{array}$ & 23.1 & 25.5 & 11.9 & 30.4 & 8.9 & 0.3 \\
\hline 22 & ESE3 & $\begin{array}{l}\text { Scientific evidence indicates that dinosaurs and humans lived at the } \\
\text { same time in the past. }{ }^{\text {a }}\end{array}$ & 13.1 & 20.5 & 19.1 & 27.9 & 18.7 & 0.6 \\
\hline 23 & ESE4 & The majority of scientists favor evolution over other explanations for life. & 18.2 & 27.3 & 20.9 & 11.9 & 21.1 & 0.5 \\
\hline
\end{tabular}

$(48.0 \%, n=476)$. In terms of urban-centric classification, rural designated high schools housed the majority of participants $(49.5 \%, n=492)$ while city designated schools held the minority $(2.5 \%, n=25)$. Cronbach's alpha of 0.848 was identified for the 23-statement BEL Survey which indicates that the internal reliability of the survey is acceptable. Additionally, if any one statement is deleted, the reliability coefficient does not decrease by more than 0.014 , thus maintaining the survey's internal reliability.

\subsection{Significant Differences}

Chi-square statistics were used to identify significant differences $(p<0.05)$ among variables related to the 42 public high school containing the study's 993 student participants and the sum total 474 public high schools 
located within the study area (see Table 2). A comparison between the two sets of schools focused on two variables: (a) distribution of student ADM (Institute of Education Sciences National Center for Educational Statistics [IESNCES], 2010a), and (b) urban-centric classification (IESNCES, 2010b). A chi-square goodness-of-fit statistical analysis revealed no significant difference $(p<0.05)$ between the two high school groups for ADM distribution, $\chi^{2}(4, N=42)=4.29, p=0.37$. This result indicates that the 42 public high schools from which the student participants originated were representative of the collective 474 public high schools within the study region for ADM. A chi-square goodness-of-fit statistical analysis did reveal a significant difference $(p<0.05)$ between the two public high school groups when urban-centric classification was compared, $\chi^{2}(3, N=42)=8.0$, $p=0.046$. This result indicates that the 42 public high schools from which the student participants originated were not representative of the collective 474 public high schools within the study area in terms of urban-centric classification. A 14.45 confidence interval at a 95\% confidence level was identified for the sample of high schools $(n=42)$ representing the study's 993 student participants compared to the number of public high schools located within the study region $(N=474)$.

No significant difference was identified between the ratio of males (48.3\%) to females $(51.7 \%)$ in the study population $(n=991)$ when compared to the ratio of males $(51.5 \%)$ to females $(48.5 \%)$ within the study region $\left(N=176,679\right.$; IESNCES, 2010c) $\chi^{2}(1, N=991)=0.41, p=0.52$. However, a significant difference was identified between the ratios of students' ethnicities in the participant population when compared to those of all public high school students within the study region (see Table 1; IESNCES, 2010c), $\chi^{2}(4, N=997)=12.2, p=0.02$. These results indicate that the gender ratio of student participants was representative of the gender ratio for all students within the study region whereas participants' ethnicity ratios were not. The difference between participants' actual and expected ethnicity ratios may, in part, be attributed to a difference in ethnicity ratios between urban and rural settings in Oklahoma (U.S. Census Bureau, 2009). Rural settings in Oklahoma possess greater percentages of White non-Hispanics (+9.3\%) and American Indians (+3.3\%) and lesser percentages of Hispanics (-6.0\%), Asians (-1.3\%), and Black non-Hispanics $(-7.2 \%)$ as opposed to urban settings (U.S. Census Bureau, 2009). This study possesses a higher than expected percentage of participants' public high schools designated in town and rural locations (+3.4\%) and a lower than expected percentage of participants' schools designated in suburban and city locations $(-3.4 \%)$. This discrepancy may have resulted in higher percentages of White non-Hispanic and American Indian participants and lower percentages of Hispanic, Asian, and Black non-Hispanic participants than expected.

Out of a possible maximum BEL Survey index score of 115 , student participants in this study $(N=993)$ earned a $70.34(S D=7.04)$ mean index score. Table 1 identifies participants' BEL-MIS compared to specific variables. Although previous studies have shown that student misconceptions concerning science can differ significantly based on multiple variables including geographical region, religious background, generation, gender, and age (Almquist \& Cronin, 1988; Losh et al., 2003; Morrison \&Lederman, 2003; Palmer, 1999), this study found no significant differences $(p<0.05$ ) between students' BEL-MIS when related to students' gender, grade, ethnicity, or public high schools' urban-centric location or ADM. However, a significant difference was revealed between students' BEL-MIS when compared to two sets of biological evolution knowledge self-rating descriptors: $\operatorname{good}(M=72.55, S D=8.46, n=146)$ versus poor $(M=68.92, S D=6.53, n=143)$ and good versus fair $(M=69.49, S D=6.50, n=224)$. This result seems to indicate a direct correlation between students' selfrating of biological evolution knowledge and their actual knowledge as students' BEL-MIS increased sequentially with the ratings poor $(M=68.92)$, fair $(M=69.49)$, average $(M=70.56)$, and $\operatorname{good}(M=72.55)$. However, readers should proceed with caution as those students who selected the excellent descriptor for their biological evolution knowledge produced a BEL-MIS of just 70.08, lower than both the good and average descriptor categories. This result may in part be due to the small sample size of students who selected the excellent descriptor $(n=36)$ as opposed to the sample sizes of students who selected the other four descriptors ( $n=143$ to 433$)$.

\subsection{Science, Scientific Methodology and Terminology}

Table 3 lists each BEL Survey statement and accompanying participant percent response. The combined percent responses of participants highlighted in gray identifies the percentage of participants who held the accompanying statement's associated misconception whereas the combined pair of percent responses in the adjacent nonhighlighted regions (either 1 and 2 or 3 and 4) identifies the percentage of participants who held the correct concept as related to the statement. Table 4 identifies interactions between participants' responses to selected 
Table 4. Interaction between responses to selected BEL survey statements.

\begin{tabular}{|c|c|c|c|c|c|c|c|c|c|c|}
\hline \multirow[t]{2}{*}{ Statement } & \multirow[t]{2}{*}{ Interaction statement } & \multicolumn{3}{|c|}{ Agree with statement ${ }^{*}$} & \multicolumn{3}{|c|}{ Disagree with statement ${ }^{*}$} & \multicolumn{3}{|c|}{ Undecided about statement ${ }^{*}$} \\
\hline & & $\mathrm{A} \%$ & $\% \mathrm{D}$ & $\% \mathrm{U}$ & $\% \mathrm{~A}$ & $\% \mathrm{D}$ & $\% \mathrm{U}$ & $\% A$ & $\% \mathrm{D}$ & $\% \mathrm{U}$ \\
\hline \multicolumn{11}{|c|}{ Science, scientific method and terminology } \\
\hline 1 & 5 & 57.2 & 35.7 & 7.1 & 15.5 & 82.8 & 1.7 & 0.0 & 0.0 & 100.0 \\
\hline 2 & 4 & 91.1 & 7.1 & 1.8 & 50.0 & 40.0 & 10.0 & 0.0 & 0.0 & 0.0 \\
\hline \multicolumn{11}{|c|}{ Intentionality of evolution } \\
\hline \multirow[t]{3}{*}{6} & 7 & 36.8 & 63.2 & 0.0 & 18.5 & 79.6 & 1.9 & 0.0 & 0.0 & 100.0 \\
\hline & 9 & 42.1 & 57.9 & 0.0 & 23.6 & 74.6 & 1.8 & 0.0 & 100.0 & 0.0 \\
\hline & 19 & 15.8 & 84.2 & 0.0 & 5.5 & 94.5 & 0.0 & 0.0 & 100.0 & 0.0 \\
\hline \multirow[t]{2}{*}{7} & 8 & 64.7 & 23.5 & 11.8 & 89.3 & 10.7 & 0.0 & 100.0 & 0.0 & 0.0 \\
\hline & 10 & 58.8 & 23.5 & 17.7 & 87.5 & 10.7 & 1.8 & 100.0 & 0.0 & 0.0 \\
\hline 10 & 8 & 88.7 & 11.3 & 0.0 & 60.0 & 40.0 & 0.0 & 50.0 & 0.0 & 50.0 \\
\hline \multicolumn{11}{|c|}{ Nature of evolution } \\
\hline \multirow[t]{2}{*}{11} & 13 & 44.0 & 54.0 & 2.0 & 13.0 & 82.6 & 4.4 & 0.0 & 100.0 & 0.0 \\
\hline & 14 & 94.0 & 6.0 & 0.0 & 82.6 & 17.4 & 0.0 & 66.7 & 0.0 & 33.3 \\
\hline 12 & 14 & 85.3 & 11.8 & 2.9 & 92.9 & 7.1 & 0.0 & 0.0 & 0.0 & 0.0 \\
\hline 13 & 14 & 92.0 & 8.0 & 0.0 & 89.8 & 8.2 & 2.0 & 50.0 & 50.0 & 0.0 \\
\hline \multicolumn{11}{|c|}{ Mechanisms of evolution } \\
\hline \multirow[t]{5}{*}{15} & 9 & 23.9 & 76.1 & 0.0 & 85.7 & 14.3 & 0.0 & 0.0 & 50.0 & 50.0 \\
\hline & 16 & 37.3 & 62.7 & 0.0 & 85.7 & 14.3 & 0.0 & 0.0 & 100.0 & 0.0 \\
\hline & 17 & 7.5 & 92.5 & 0.0 & 28.6 & 71.4 & 0.0 & 0.0 & 50.0 & 50.0 \\
\hline & 18 & 62.7 & 32.8 & 4.5 & 14.3 & 71.4 & 14.3 & 0.0 & 50.0 & 50.0 \\
\hline & 19 & 3.0 & 97.0 & 0.0 & 42.9 & 57.1 & 0.0 & 50.0 & 50.0 & 0.0 \\
\hline \multicolumn{11}{|c|}{ Evidence supporting evolution } \\
\hline \multirow[t]{5}{*}{20} & 2 & 89.8 & 10.2 & 0.0 & 45.8 & 54.2 & 0.0 & 33.3 & 66.7 & 0.0 \\
\hline & 4 & 98.0 & 0.0 & 2.0 & 45.8 & 50.0 & 4.2 & 33.3 & 33.3 & 33.3 \\
\hline & 21 & 14.3 & 79.6 & 6.1 & 41.7 & 58.3 & 0.0 & 0.0 & 100.0 & 0.0 \\
\hline & 22 & 14.6 & 81.2 & 4.2 & 41.7 & 50.0 & 8.3 & 66.7 & 0.0 & 33.3 \\
\hline & 23 & 79.6 & 12.2 & 8.2 & 75.0 & 25.0 & 0.0 & 33.3 & 0.0 & 66.7 \\
\hline
\end{tabular}

Note: Table 4 compares participants' interaction statement responses to those of a specified statement. $A=$ agreed; $D=$ disagreed; $U=$ undecided. Example: Of those participants who agreed with statement 1, 57.2\% agreed with statement 5 . *Percent response may not total $100.0 \%$ due to rounding.

statements. Statements 1 through 5 address the general opinions of student participants concerning science, scientific methodology and terminology as they relate to evolutionary theory. Figure 1 illustrates the responses to each of these statements.

The word theory is perhaps the most misunderstood word in science (Scott, 2004). In everyday usage, guess or hunch-terms that imply speculation or conjecture-are synonyms for theory. Yet according to the National Academy of Sciences (NAS), a scientific theory is defined as "a well-substantiated explanation of some aspect of the natural world that can incorporate facts, laws, inferences, and tested hypotheses” (1998: p. 7). Students 


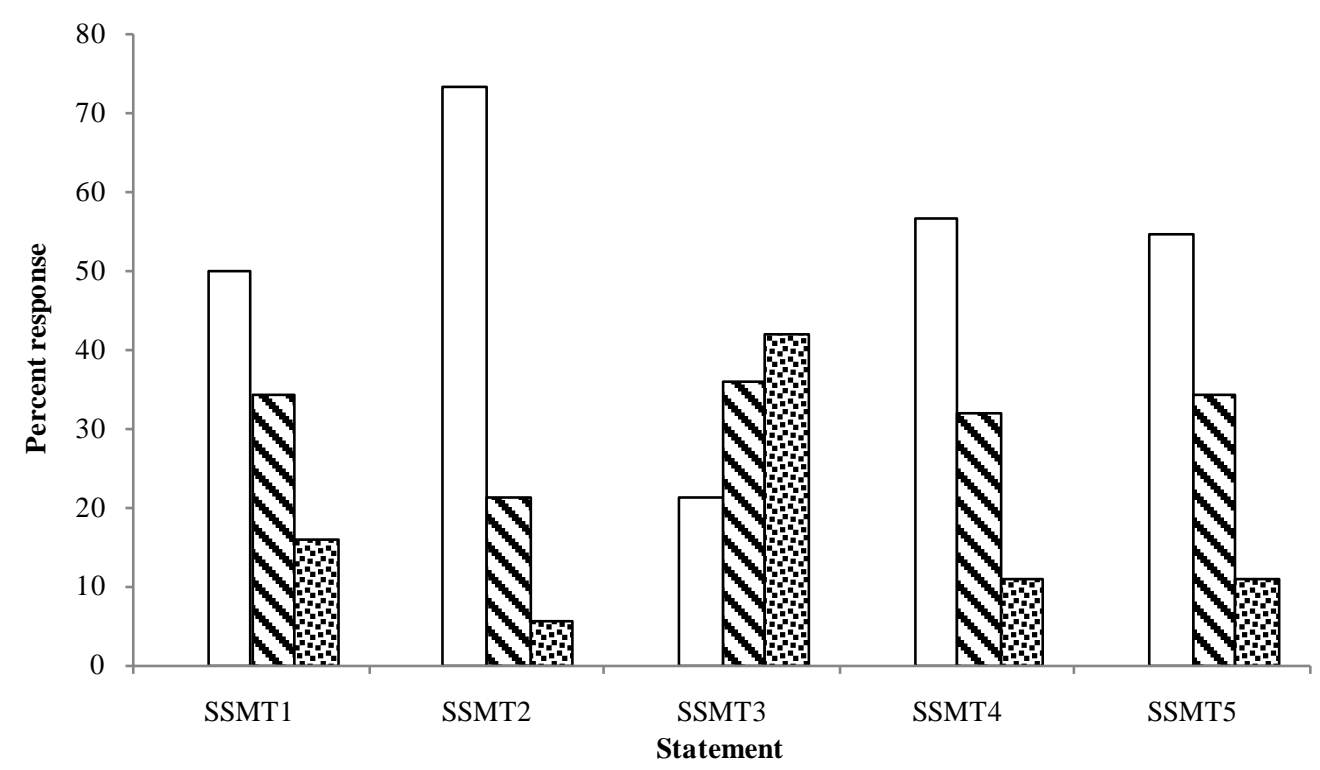

Figure 1. Percent response to science, scientific method and terminology statements. Clear bar = "strongly agree/somewhat agree"; diagonal bar = "strongly disagree/somewhat disagree"; dotted bar = "undecided/never heard of it"

who possess misconceptions of scientific theory typically understand theory in the speculative sense (Alters \& Alters, 2001; Dagher \& BouJaoude, 1997; Smith \& Sullivan, 2007) as in evolution is only a theory. Responses to statement 1 ("A scientific theory that explains a natural phenomenon can be defined as a 'best guess' or 'hunch'”) reveal only 34.0\% $(n=338)$ of students correctly interpreted the term theory as used in a scientific context whereas $50.0 \%(n=496)$ failed to differentiate between the scientific concept of theory and its usage in common vernacular. Statement 5 ("Evolution cannot be considered a reliable explanation because evolution is only a theory") fared little better with $34.2 \%(n=340)$ correctly relating the accurate definition of a scientific theory to the theory of evolution while $54.8 \%(n=544)$ were unable to do so. Analysis found $40.2 \%(n=136)$ of participants who disagreed with statement $1(n=338)$ also in disagreement with statement 5 , indicating that only $13.8 \%$ of participants $(n=136)$ who completed both statements 1 and $5(n=987)$ understand the term theory in the scientific context and correctly apply that meaning to the theory of evolution. Of those participants who appear to possess an accurate conception of a scientific theory as indicated by their negative response to statement $1(n=338), 50.3 \%(n=170)$ contend that evolution cannot be considered a reliable explanation because evolution is only a theory. And, of those participants in agreement with statement $1(n=496), 57.7 \%(n=286)$ were consistent in their misconception by also agreeing with statement 5 . This outcome indicates that for these participants-representing 28.8\% ( $n=286)$ of all participants - the scientific use of theory does not differ from that of common usage (as in "best guess" or "hunch") and therefore evolution cannot be deemed reliable because it is only a theory. Students possessing such a concept of theory no doubt consider evolution to be a weak science.

A basic premise in evolutionary theory is the large expanse of time required for evolutionary processes to occur. Students are known to hold misconceptions related to the evolutionary time scale with many believing that evolution occurs over centuries rather than tens and hundreds of millennia (Robbins \& Roy, 2007). Dating techniques provide evidence of the timeline of evolution. Alters and Alters (2001) lamented the number of students who have come to believe that dating techniques are questionable while Scott (2004) detailed 20 such misconceptions. Based on these misconceptions, students tend to view calculated dates as inaccurate. However, this study revealed a relatively high percentage of participants $(73.3 \%, n=727$ ) who agreed with statement 2 ("The scientific methods used to determine the age of fossils and the earth are reliable”) while $21.2 \%(n=210)$ held to the misconception. A comparative statement, statement 4 ("The Earth is old enough for evolution to have occurred”), received a less favorable response with only 56.8\% $(n=564)$ in agreement while $31.7 \%(n=315)$ disagreed.

With $62.3 \%(n=453)$ of participants who agreed with statement $2(n=727)$ also agreeing with statement 4 , a very small positive correlation was revealed between participants' understanding of the reliability of dating 
techniques (statement 2) and the age of the Earth (statement 4), $r(984)=0.06, p>0.05$ ). Such a small correlation, however, indicates much diversity in student responses as evidenced by $29.0 \%(n=288)$ of participants who presented conflicting opinions of statements 2 and 4 , with $8.9 \%(n=88)$ disagreeing with statement 2 while agreeing with statement 4 . While these individuals adhere to the misconception that scientific dating methods are not reliable, they do understand that the Earth is old enough for evolution to have occurred. Conversely, 20.1\% $(n=200)$ agreed with statement 2 while at the same time disagreed with statement 4 . Although these participants understand that scientific dating techniques are reliable they possess the conflicting opinion that the Earth is not old enough for evolution to have occurred.

The second law of thermodynamics explains that in a closed system energy tends to travel from organized to disorganized states in the form of heat (Futuyma, 1995). If students fail to understand that life operates within an open system with a constant inflow of energy, a commonly held misconception develops which describes evolution in violation of the second law of thermodynamics. Such a misconception precludes complex organisms evolving from simpler ones (Alters \& Alters, 2001; Berra, 1990; Futuyma. 1995; Scott, 2004; Smith \& Sullivan, 2007) as was evident in $21.4 \%(n=212)$ of participants who agreed with statement 3 ("According to the second law of thermodynamics, complex life forms cannot evolve from simpler life forms"). A combined $42.8 \%$ of students $(n=425)$ either claimed undecided/never heard of it or failed to state an opinion. Statement 3 generated the greatest percentage of undecided/never heard of it responses of all the BEL Survey's 23 statements with a $41.9 \%(n=416)$ response rate.

Participants possessed a $46.8 \%$ mean rate of understanding coupled with a $35.8 \%$ mean misconception rate in response to the five Science, Scientific Methodology and Terminology survey statements while $17.4 \%(n=173)$ of participants per statement were undecided or did not respond. Expressing no misconceptions related to the five statements were $13.6 \%(n=135)$ of participants $(N=993)$ while $29.6 \%(n=294)$ held one misconception; 30.1\% ( $n=299)$, two misconceptions; $19.3 \%(n=192)$, three misconceptions; 5.9\% $(n=59)$, four misconceptions; and 1.4\% $(n=14)$ held misconceptions related to each of the five statements. Collectively, $86.4 \%(n=$ 858) of participants held one or more misconceptions related to the Science, Scientific Methodology and Terminology category statements.

\subsection{Intentionality of Evolution}

The five statements of the BEL Survey Intentionality of Evolution section were designed to measure participants' misconceptions of biological evolution intentionality. Misconceptions associated with evolution intentionality subscribe a type of conscious will and directive to the mechanisms of evolution. Figure 2 illustrates the responses

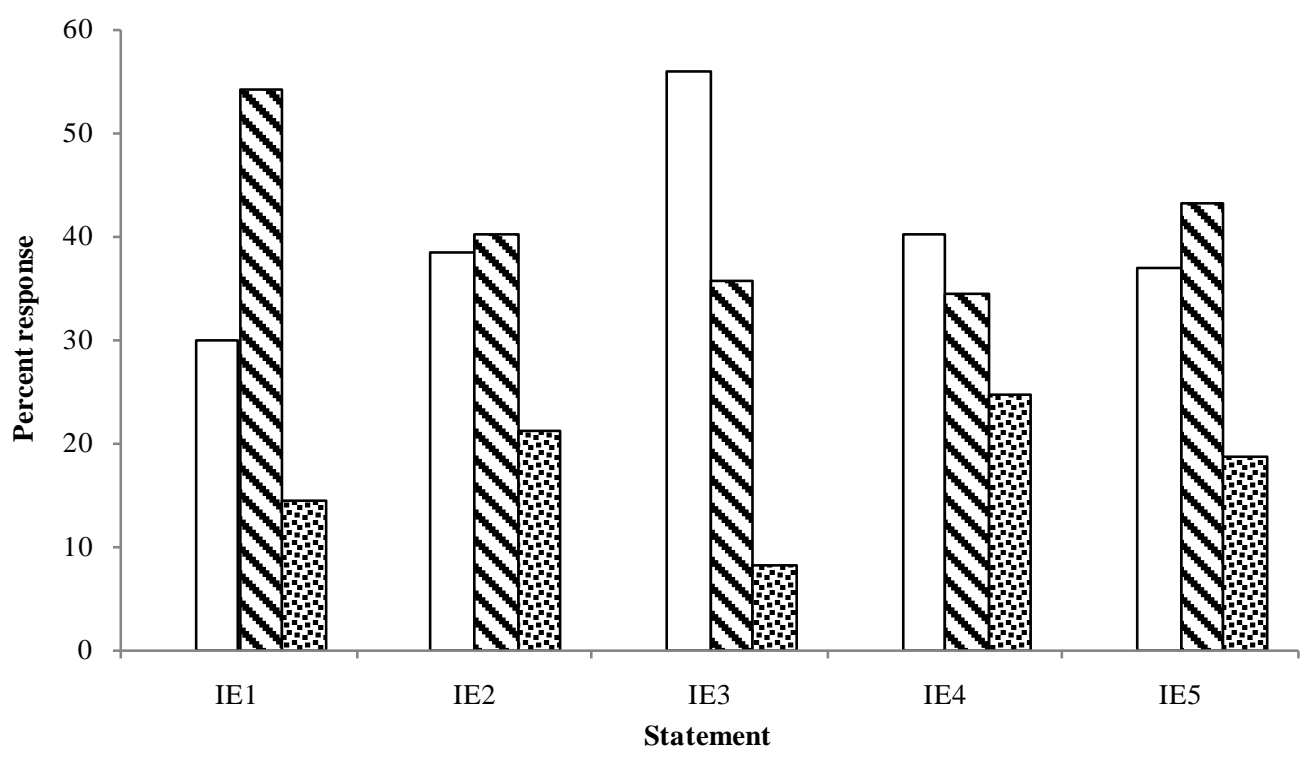

Figure 2. Percent response to intentionality of evolution statements. Clear bar = "strongly agree/ somewhat agree"; diagonal bar = "strongly disagree/somewhat disagree"; dotted bar = "undecided/never heard of it”. 
to each of these statements. Responses from statement 6 ("Evolution always results in improvement”) reveal that 54.1\% ( $n=537)$ of participants disagreed with the statement and therefore understand that the process of evolution does not always result in improvement, while $30.0 \%(n=298)$ agreed with statement 6 , indicating an adherence to the misconception that evolution always does result in improvement. Statement 7 ("Members of a species evolve because of an inner need to evolve”) found $40.1 \%(n=398)$ in disagreement while $38.4 \%(n=381)$ agreed, indicating that a slight majority of participants understand that evolution is not based on need. A small positive correlation, $r(972)=0.23, p<0.01$, exists between results for statements 6 and 7 with $46.2 \%(n=248)$ of participants who disagreed with statement $6(n=537)$ also in disagreement with statement 7 . Of those participants who held the misconception identified in statement $6,48.7 \%(n=145)$ also shared the misconception described in statement 7 . This result indicates a tendency among these students to view evolutionary processes as deterministic in nature with improvement as their goal.

Participant agreement with statement 9 ("If webbed feet are being selected for, all individuals in the next generation will have more webbing on their feet than do individuals in their parents' generation”) also implies a deterministic view of evolutionary mechanisms. The majority of students, $40.3 \%(n=400)$, did reveal such a misconception by agreeing with statement 9 , while $34.4 \%(n=341)$ were in disagreement. A small positive correlation, $r(968)=0.167, p<0.01$ was disclosed between participants' responses to statements 6 and 9 with 19.9\% ( $n$ $=193)$ of participants who responded to both statements $(n=968)$ possessing neither misconception. However, $14.4 \%(n=139)$ of participants claimed both the misconceptions associated with statements 6 and 9 . Of those participants who disagreed with statement $6(n=537), 40.4 \%(n=217)$ agreed with statement 9 , and of those participants who disagreed with statement $9(n=341)$, 28.7\% $(n=98)$ agreed with statement 6 . These results reveal that 32.5\% $(n=315)$ of participants who answered both statements 6 and $9(n=968)$ possessed contradictory conceptions in regard to intentionality of evolution as related to these statements.

Statement 10 ("Evolution cannot cause an organism's traits to change within its lifetime") produced $37.1 \%$ ( $n=$ 368) agreement among participants, with $43.2 \%(n=429)$ in disagreement, signifying that the majority of participants adhere to the misconception that evolutionary processes can produce change in individual organisms during their lifetimes. Among those participants in agreement with statement 10, 42.4\% $(n=156)$ also disagreed with statement 7 suggesting that only $16.0 \%(n=156)$ of those participants who addressed both statements 10 and $7(n=978)$ correctly understand that evolution is not driven by need and cannot cause an organism's traits to change within its lifetime. However, $44.0 \%(n=175)$ of those participants who disagreed with statement 7 $(n=398)$ also disagreed with statement 10 . While these participants understand that evolution is not driven by need, they hold the misconception that evolution can act upon an organism's traits during its lifetime. Holding misconceptions related to both statements 7 and 10 were $18.7 \%(n=183)$ of participants, disclosing the mistaken idea that members of a species evolve because of an inner need to evolve and these needs can be fulfilled via the process of evolution during the lifetime of the organism. A small positive correlation exists between statements 7 and 10, $r(978)=0.104, p<0.01$, indicative of the fact that $50.6 \%(n=502)$ of participants $(N=$ 993) possessed at least one misconception related to statements 7 and 10.

Statement 8 ("Traits acquired during the lifetime of an organism--such as large muscles produced by body building — will not be passed along to offspring”) found agreement among 55.9\% ( $n=555)$ of participants as opposed to $35.7 \%(n=354)$ who held to the Lamarckian misconception of inheritance via acquired characteristics. A small positive correlation of $r(979)=0.124, p<0.01$ was discovered between participant responses to statements 8 and 10 ("Evolution cannot cause an organism's traits to change within its lifetime"). Of those participants in agreement with statement $10(n=368), 59.8 \%(n=230)$ also agreed with statement 8 . These results indicate that only $23.2 \%(n=230)$ of participants correctly understand that characteristics acquired by an organism during its lifetime are not produced by evolutionary processes nor can acquired traits be passed along to the next generation. Of those participants disagreeing with statement $10(n=429)$, 38.9\% $(n=167)$ disagreed with statement 8 . These 167 individuals, representing $16.8 \%$ of the participant population, not only adhere to the misconception that traits acquired during the lifetime of an organism can be passed on to offspring but that such traits can be produced via evolutionary processes as well. Similarly, 38.1\% $(n=145)$ of the 381 participants who agreed with statement 7 also disagreed with statement 8 . These individuals, representing $14.6 \%$ of student participants, adhere to the two related misconceptions that evolution occurs as a response to need and traits acquired during the lifetime of an organism can be inherited by offspring.

This tendency of secondary school students toward biological evolution explanations based on purpose is common and persistent throughout the literature (e.g., Alters \& Nelson, 2002; Beardsley, 2004; Bizzo, 1994; 
Clough \& Wood-Robinson, 1985; Deadman \& Kelly, 1978; Geraedts \& Boersma, 2006; Jensen \& Finley, 1996; Jiménez-Aleixandre, 1992; Kampourakis \& Zogza, 2008, 2009; Passmore \& Stewart, 2002; Pedersen \& Halldén, 1992; Prinou et al., 2008; Samarapungavan \& Wiers, 1997; Settlage, 1994; Shtulman, 2006; Southerland et al., 2001; Tamir \& Zohar, 1991) and even into postsecondary education (Kelemen \& Rosset, 2009). In fact, in a study of university nonmajor biology students, Jensen and Finley (1996) identified the most common misconception responses were related to purposeful evolution.

Collectively, participants own a $44.3 \%$ mean rate of understanding coupled with a $37.5 \%$ mean misconception rate in response to the five Intentionality of Evolution survey statements while $18.2 \%$ of participants per statement were undecided or did not respond. Expressing no misconceptions related to the five statements were 12.8\% ( $n=127)$ of participants while $28.1 \%(n=279)$ held one misconception; $28.9 \%(n=287)$, two misconceptions; $21.0 \%(n=208)$, three misconceptions; 7.5\% $(n=75)$, four misconceptions; and $1.7 \%(n=17)$ held misconceptions related to each of the five statements. Collectively, $87.2 \%(n=866)$ of participants held one or more misconceptions related to the Intentionality of Evolution statements.

\subsection{Nature of Evolution}

Participants' conceptions related to the nature of evolution, including the roles of randomness, the environment in evolutionary processes, and adaptation, were addressed in the Nature of Evolution statements, 11 - 14. Figure 3 illustrates the responses to each of these statements. Responses from statement 11 ("New traits within a population appear at random") were evenly split with $41.2 \%(n=409)$ of participants in agreement whereas $41.6 \%$ $(n=413)$ adhered to the misconception. Statement 13 ("Evolution is a totally random process") resulted in $25.9 \%$ $(n=257)$ of participants agreeing with the misconception while $51.5 \%(n=511)$ disagreed. A medium positive correlation of $r(984)=0.27, p<0.01$ between statements 11 (positive) and 13 (negative) reveals much diversity of opinion among participants as 59.5\% $(n=591)$ possessed at least one misconception for the combined statements. Of those students in agreement with statement $11(n=409)$ who correctly identified that new traits appear in the population at random, $35.9 \%(n=147)$ claimed that evolution is a totally random process, adhering to the misconception identified in statement 13. Conversely, of those participants who disagreed with statement $11(n=413), 19.1 \%(n=79)$ also agreed with statement 13 , presenting the conflicting misconceptions that evolution is a totally random process, yet new traits within a population do not appear at random. These elevated levels of misconception among participants concerning the concept of randomness are a bit disconcerting as Isaak (2003) contends there is no other misconception which is a better indication of lack of understanding of evolution than the misconception that evolution proceeds by random chance. Although randomness does play a

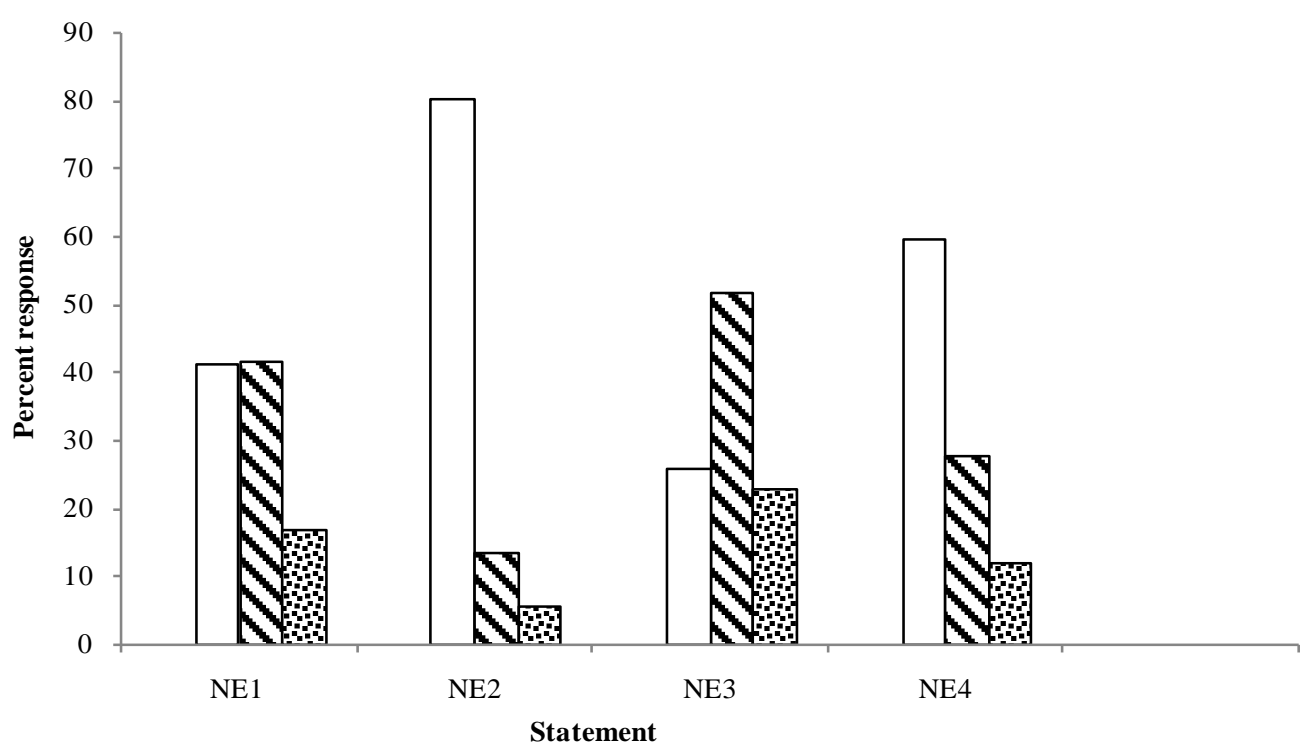

Figure 3. Percent response to nature of evolution statements. Clear bar = "strongly agree/somewhat agree"; diagonal bar = "strongly disagree/somewhat disagree"; dotted bar = "undecided/never heard of it”. 
role in pivotal evolutionary mechanisms such as the origination of variations, with the environment selecting specific variations within populations, evolution in totality is a nonrandom process (Smith \& Sullivan, 2007).

Statement 14 ("The environment determines which traits are best suited for survival") found a majority of participants correctly agreeing $(59.8 \%, n=594)$ while $27.5 \%(n=273)$ disagreed. Of those participants agreeing with statement 11 ( $n=409$; "New traits within a population appear at random"), 62.1\% $(n=254)$ also agreed with statement 14 revealing that $25.6 \%(n=254)$ of participants correctly understand these two major premises of natural selection. Holding to one misconception associated with statements 11 and 14, however, were 56.7\% $(n=563)$ of participants while $12.4 \%(n=123)$ revealed misconceptions associated with both statements. Possessing accurate concepts for both statements 13 and 14 were $34.1 \%$ of participants $(n=339)$. Of those participants agreeing with statement $13(n=257), 58.8 \%(n=151)$ also agreed with statement 14 . While these students understand that the environment plays a key role in determining which traits are best suited for survival, they hold the contradictory view that evolution is a totally random process. Conversely, of those individuals who correctly disagreed with statement $13(n=511), 26.4 \%(n=135)$ also disagreed with statement 14 . For these participants, evolution is not a totally random process, yet the environment fails to play a role in trait survivability.

Statement 12 ("Individual organisms adapt to their environments") found 13.4\% ( $n=133)$ of participants in disagreement whereas a large $80.1 \%(n=796)$ were in agreement, claiming the associated misconception. The relatively high percentage of participants possessing this misconception as compared to the average misconception rate (39.1\%) raised concern. During the BEL Survey design, it was apparent that respondents might interpret the term adapt in a nonevolutionary context such as "to adjust (oneself) to a new or changing circumstances" (Guralnick 1980: p. 15), as in a herd of elk moving to lower elevations in the summer to forage, as opposed to the intended evolutionary usage of the term whereas populations of organisms-not individuals—adapt to their environment via evolutionary mechanisms such as natural selection. In order to reduce the probability of this occurrence, in the BEL Survey participants' instructions section emphasis was placed on informing participants that “... your opinions concerning biological evolution concepts will be identified." Whether all participants adhered to this admonition (or understood) is, of course, unknown, so there may be participants who were recognized as adhering to the misconception revealed by statement 12 when in reality they may have failed to address the term adapt in an evolutionary context. Since these students entered the study with little academic exposure to biological evolution concepts, it is reasonable to assume that such may be the case.

Of those in disagreement with statement $12(n=133), 48.9 \%(n=65)$ were in agreement with statement 14 ("The environment determines which traits are best suited for survival"). While these individuals correctly attributed the role of adaptation to the environment rather than to the individual organism, they represent only $6.7 \%$ of the total number who responded to both statements 12 and $14(n=975)$. Of those individuals disagreeing with statement $12(n=133)$ 39.8\% $(n=53)$ also disagreed with statement 14. For these participants, individual organisms do not adapt to their environments yet the environment fails to play a role in determining the survivability of traits and hence the development of adaptations. Of those participants agreeing with statement $12(n=$ 796), $64.6 \%(n=514)$ also agreed with statement 14 . This group of students confers the ability to adapt to the environment to individual organisms with the environment, in turn, determining which traits are best suited for survival. Not surprisingly, with the large number of misconceptions evident in participants concerning statements 12 (negative) and 14 (positive) a medium positive correlation resulted, $r(975)=0.28, p<0.01$.

Participants averaged a $41.5 \%$ mean rate of understanding, a $43.8 \%$ mean misconception rate, and $14.7 \%$ mean undecided or nonresponse rate to the four Nature of Evolution survey statements. Expressing no misconceptions related to the four statements were 5.9\% $(n=59)$ of participants while $32.1 \%(n=319)$ held one misconception; 44.6\% $(n=443)$, two misconceptions; $15.5 \%(n=154)$, three misconceptions; and $1.8 \%(n=18)$ held misconceptions related to each of the four statements. Collectively, $94.1 \%$ of participants $(n=934)$ held one or more misconceptions related to the four Nature of Evolution statements.

\subsection{Mechanisms of Evolution}

Statements 15 through 19 address the opinions of student participants concerning mechanisms that lead to evolutionary change. Figure 4 illustrates the responses to each of these statements. One of the primary mechanisms for evolutionary change is natural selection which determines which members of a population will survive long enough to reproduce and transmit their genes to the next generation. The theory of natural selection calls for 


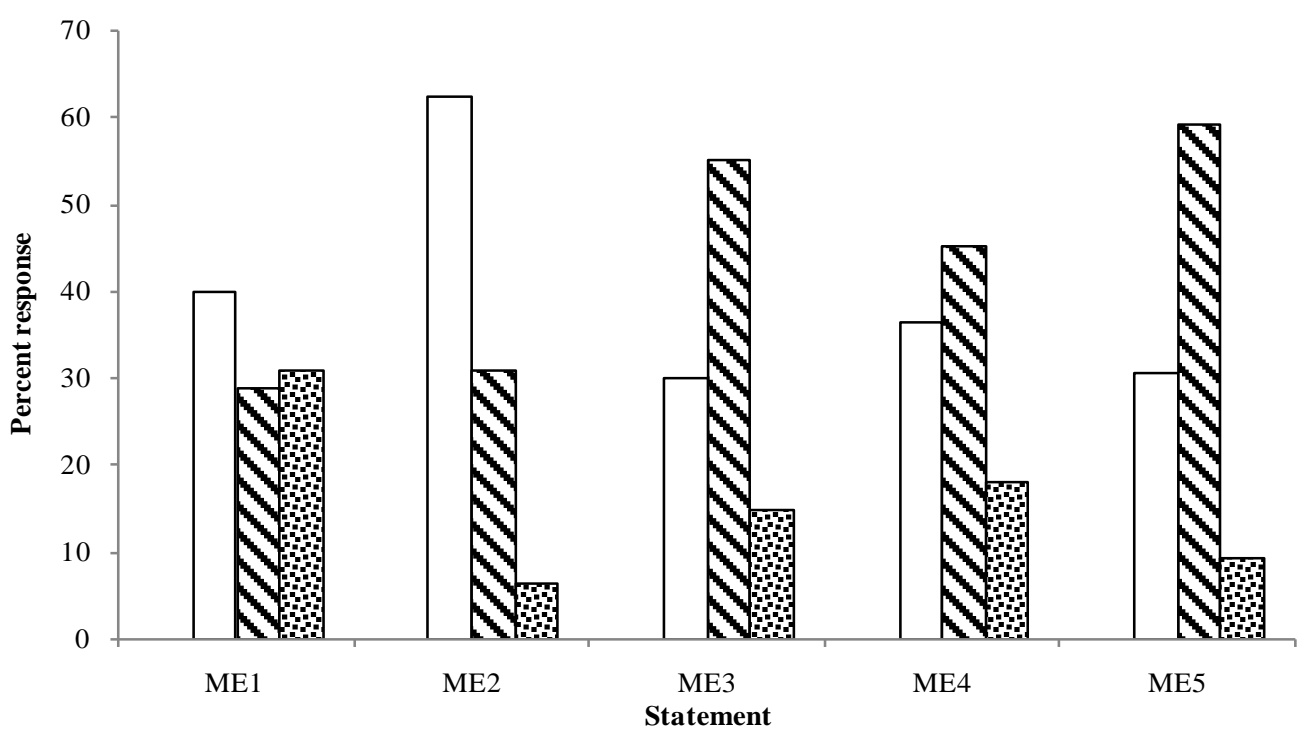

Figure 4. Percent response to mechanisms of evolution statements. Clear bar = "strongly agree/ somewhat agree"; diagonal bar = "strongly disagree/somewhat disagree"; dotted bar = "undecided/never heard of it”.

variations within a population. Those population members possessing variations that give them an advantage in the environment in which they reside are thus granted a reproductive advantage over those members with less advantageous variations. The majority of students $(40.1 \% ; n=398)$ agreed with statement 15 ("Variation among individuals within a species is important for evolution to occur") whereas $28.7 \%(n=285)$ held the misconception that variation among members of a species is not important to evolutionary processes. These finding concur with the literature which indicates that students may not view genetic variation as important to evolution, even though such variation is essential to evolution taking place (Alters \& Nelson, 2002; Bishop \& Anderson, 1990; Gregory, 2009; Mayr, 1982; Rutledge \& Warden, 2002) or that variations only affect outward appearance, and do not influence survival (Anderson et al., 2002).

The literature is replete with student misconceptions about both nonadaptive and adaptive traits and their respective roles in evolution. Students may incorrectly assume that traits are always beneficial and only these traits are passed along to offspring (Gregory, 2009). The majority of student participants were not of such opinion with 59.2\% ( $n=588$ ) disagreeing with statement 19 ("Only beneficial traits are passed on from parent to offspring.”) while the minority, 30.6\% ( $n=303)$, adhered to the misconception crediting hereditary mechanisms in transmitting only beneficial traits from generation to generation. Of those participants agreeing with statement $15(n=398), 60.3 \%(n=240)$ disagreed with statement 19 , yet $10.2 \%(n=101)$ of participants voiced opposite opinions by disagreeing with statement 15 while simultaneously agreeing with statement 19 . This later result appears to indicate that while these participants believe variation among individuals within a species is not important for evolution to occur, they contend that only beneficial traits are passed from parent to offspring. A small positive correlation between the two statements, $r(980)=0.13, p<0.01$, was the result of $38.8 \%(n=385)$ of participants possessing at least one misconception between statements 15 (positively oriented) and statement 19 (negatively oriented). Of those participants agreeing with statement $15(n=398), 50.5 \%(n=201)$ also agreed with statement 9 ("If webbed feet are being selected for, all individuals in the next generation will have more webbing on their feet than do individuals in their parents' generation"). While understanding the importance of variation in evolutionary change, these individuals fail to completely understand those mechanisms which contribute to variation within a population.

Of those participants disagreeing with statement 6 ("Evolution always results in improvement”), $67.6 \%$ ( $n=$ 363) also disagreed with statement 19 , producing a small positive correlation, $r(968)=0.175, p<0.01$. These students, representing $37.5 \%$ of respondents to both statements $(n=968)$, correctly understand that evolution does not always result in improvement as inheritance does not dispense only beneficial traits, but harmful traits as well. Of those individuals agreeing with statement $6(n=298), 49.0 \%(n=146)$ disagreed with statement 19 . While these individuals inaccurately view evolution as a process which always results in improvement, they 
correctly disagree that only beneficial traits are passed from generation to generation. Agreeing with both statements 6 and 19 were 127 participants, representing 13.1\% of responding participants $(n=968)$. For these participants, only beneficial traits are passed from parent to offspring, necessitating that evolution always result in improvement.

Many student-held misconceptions about natural selection involve misinterpretation of the phrase survival of the fittest, the most commonly used phrase drafted into everyday speech from the theory of evolution (Smith \& Sullivan, 2007). Darwin (1872) defined survival of the fittest as: "[The] preservation of favourable individual differences and variations, and the destruction of those which are injurious" (p. 63). Research has found that students commonly identify the meaning of survival of the fittest as directly related to physical strength, speed, intelligence or longevity (Anderson et al., 2002; Bishop \& Anderson, 1990; Robbins \& Roy, 2007), the number of mates possessed, or even the physical fighting among different species with the strongest species winning (Anderson et al., 2002). Survival of the fittest misconceptions were pervasive in student participants as $62.5 \%$ ( $n$ = 621) agreed with statement 16 (“'Survival of the fittest' means basically that 'only the strong survive”"). For those individuals agreeing with statement 15 ("Variation among individuals within a species is important for evolution to occur”; $n=398)$, 33.2\% $(n=132)$ also disagreed with statement 16 while for those participants disagreeing with statement $15(n=285), 62.1 \%(n=177)$ also agreed with statement 16 . This pair of misconceptions, evident in $17.8 \%(n=177)$ of participants $(N=993)$, is indicative of faulty understanding of both the role of variation in evolution and its relationship to fitness.

Statement 17 ("The size of the population has no effect on the evolution of a species") resulted in disagreement among 54.9\% $(n=545)$ of participants while 30.1\% $(n=299)$ revealed their misconception by affirming the statement. Of those participants in agreement with statement $15(n=398), 60.3 \%(n=240)$ also disagreed with statement 17 . While these students appear to understand that both variation among individuals within a species and population size are factors which contribute to evolution, the correlation does not reveal whether they correctly understand the relationship between population size and variation within a population. There is little doubt that $31.9 \%(n=127)$ of those participants in agreement with statement $15(n=398)$ fail to understand the relationship between population size and variation within a population as they were also in agreement with statement 17 . While these individuals may understand the role of variation in evolutionary processes, they fail to understand the contribution of population size. Likewise, a failure to grasp the relationship between variation and population size as they relate to evolution can be said of those participants who disagreed with statement $15(n=285)$ and either agreed $(n=83)$ or disagreed $(n=178)$ with statement 17 . As only $24.2 \%(n=240)$ of participants lacked misconceptions related to both statements 15 (positive orientation) and 17 (negative orientation), a small positive correlation was produced between the responses to both statements, $r(988)=0.133$, $p<0.01$.

Students may believe that complex structures such as eyes or wings could not have been formed by evolutionary processes since intermediate steps would seem to be inviable or nonfunctional (Nelson, 2008). In this study, only 36.6\% ( $n=363$ ) agreed with statement 18 ("Complex structures such as the eye could have been formed by evolution") whereas $45.0 \%(n=440)$ held to the misconception and $17.9 \%(n=178)$ were undecided. A medium positive correlation of $r(984)=0.319, p<0.01$ was identified between the responses to statements 15 (positive oriented) and 18 (positive oriented). Of those participants in agreement with statement $15(n=398)$, 47.5\% $(n=189)$ also agreed with statement 18 revealing that $19.0 \%(n=189)$ of participants correctly understand that variation among individuals within a species is an important evolutionary mechanism and that complex structures such as the eye could have been formed by evolution. Of those participants agreeing with statement $15(n=398)$ however, $42.2 \%(n=168)$ disagree with statement 18 . This result appears to indicate that while these individuals understand that variation within a species is an important mechanism of evolution, they apparently disregard the role of variation in contributing to the formation of complex structures. Of those individuals who disagreed with statement $15(n=398), 39.2 \%(n=156)$ disagreed with statement 18 as well. These individuals, representing $15.7 \%(n=156)$ of the participant population, not only fail to grasp the importance of variation in the evolution of complex structures but likewise discount the idea that complex structures can be produced via evolution.

Collectively, participants possessed a $44.3 \%$ mean rate of understanding, a $39.4 \%$ mean misconception rate, and a $16.3 \%$ mean combined undecided or nonresponse rate in response to the five Mechanisms of Evolution statements. While 9.3\% $(n=92)$ of participants expressed no misconceptions related to the five statements, $27.7 \%$ ( $n=275)$ held one misconception; 31.3\% $(n=311)$, two misconceptions; 22.2\% $(n=220)$, three misconceptions; 
8.5\% $(n=85)$, four misconceptions; and 1.0\% $(n=10)$ held misconceptions related to each of the five statements. Collectively, $90.7 \%$ of participants $(n=901)$ held one or more misconceptions related to the mechanisms of evolution statements.

\subsection{Evidence Supporting Evolution}

Although scientific evidence supporting biological evolution theory is abundant, diverse, and compelling, ranging from the fossil record to homology of DNA (Alters \& Alters, 2001; Futuyma, 1998; Ridley, 1996; Shermer, 2006), this study revealed student participants possess high rates of misconceptions concerning selected evidences supporting biological evolution. Statements 20 through 23 address the opinions of student participants concerning evidence supporting evolution. Figure 5 illustrates the responses to each of these statements.

Responses from statement 20 ("There exists a large amount of evidence supporting the theory of evolution") revealed $36.1 \%$ of participants $(n=358)$ in agreement whereas $43.9 \%(n=436)$ opted for the misconception. The most convincing evidence for the occurrence of evolution is the discovery of fossils of extinct organisms in older geological strata (Mayr, 2001). Yet, student misconceptions abound concerning fossil evidence of evolution. Based on a perceived fossil record, student misconceptions accept the coexistence of humans and dinosaurs even though evidence indicates the two groups are separated by approximately 65,000,000 years (Alters \& Alters, 2001; Alters \& Nelson, 2002). Students in this study were no exception, as this misconception was prevalent in 33.6\% $(n=334)$ of student participants (statement 22, "Scientific evidence indicates that dinosaurs and humans lived at the same time in the past"). A very small positive correlation of $r(981)=0.09, p<0.01$ was produced between statements 20 and 22 as only 17.8\% $(n=177)$ of participants lacked misconceptions related to both statements. Of the participants agreeing with statement $20(n=358), 36.0 \%(n=129)$ were in agreement with statement 22. Although these participants $(n=129)$ apparently are aware of the abundance of evidence supporting evolution theory, they are unaware--or choose to ignore--the evidence indicating the great expanse of time between the extinction of dinosaurs and the emergence of humans. Of those participants who disagreed with statement $20(n=436)$ and therefore do not claim a large amount of evidence exists supporting evolution, $33.3 \%(n=145)$ agreed with statement 22, contending that scientific evidence indicates that dinosaurs and humans were contemporaries. These 145 individuals, holding to misconceptions associated with both statements 20 and 22, represent $14.6 \%$ of participants $(N=993)$. Conversely, 50.0\% $(n=218)$ of individuals disagreeing with statement $20(n=436)$, also disagreed with statement 22. Although these students possess misconceptions concerning the abundance of evidence supporting evolutionary theory, they disavow the idea of dinosaurs and humans coexisting.

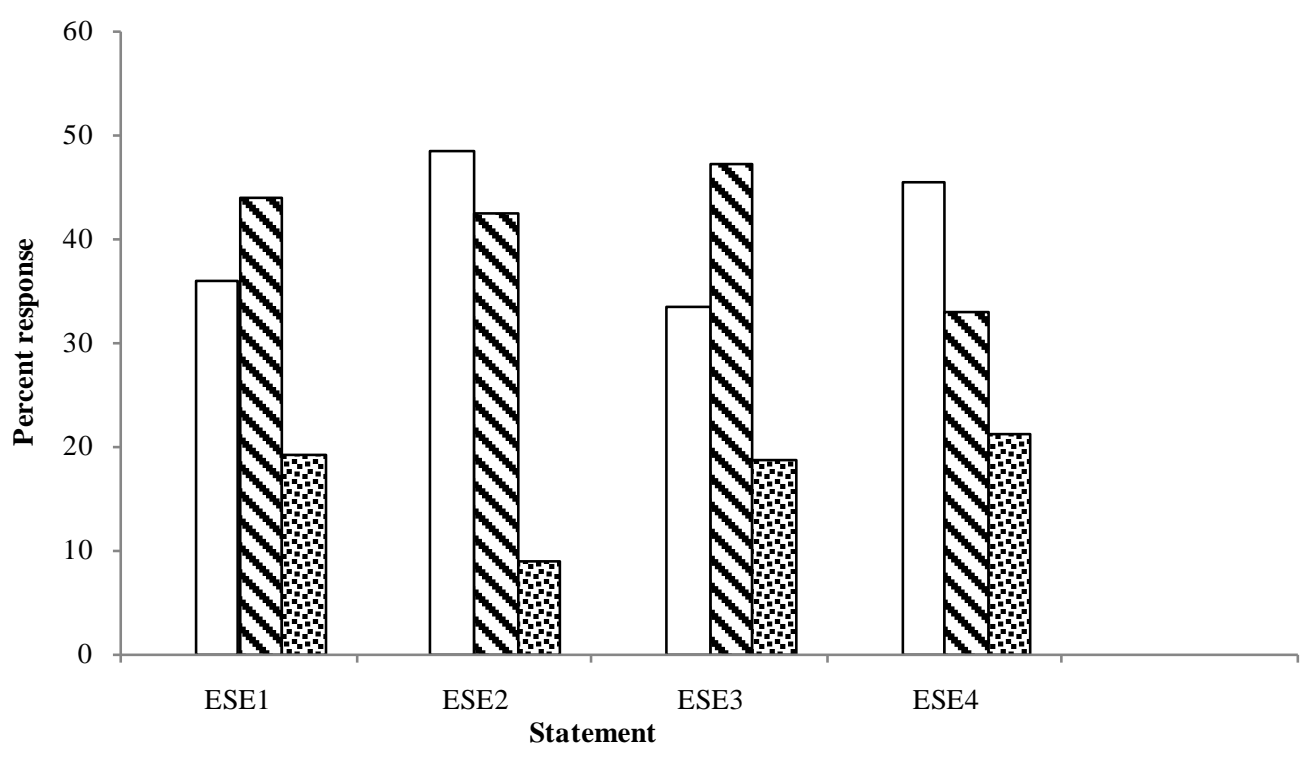

Figure 5. Percent response to evidence supporting evolution statements. Clear bar = "strongly agree/somewhat agree"; diagonal bar = "strongly disagree/somewhat disagree"; dotted bar= "undecided/never heard of it”. 
Correlation coefficients were produced between statement 20 and statements 2 ("The scientific methods used to determine the age of fossils and the Earth are reliable") and 4 ("The Earth is old enough for evolution to have occurred"). Statements 20 and 2 revealed a very small positive correlation of $r(984)=0.10, p<0.01$ with $28.3 \%$ $(n=281)$ of participants agreeing with both positive statements and $11.3 \%(n=112)$ in disagreement with both statements. For this later group of participants, the failure to accept the existence of a large amount of evidence supporting the theory of evolution may at least partially be a direct result of their questioning the reliability of scientific dating methods. A medium positive correlation, $r(979)=0.36, p<0.01$, was discovered between participants' responses to statements 20 and 4 with $27.9 \%(n=277)$ agreeing with both positive statements whereas 20.1\% $(n=204)$ disagreed with both statements. For those participants adhering to misconceptions associated with both statements 20 and 4, 29.4\% $(n=60)$ also held to the misconception identified by statement 2 . These 60 individuals, representing $6.0 \%$ of all participants, are consistent in their multiple misconceptions, denying the large volume of evidence supporting the theory of evolution while at the same time asserting that scientific dating methods are not reliable and the Earth is not old enough for evolution to have occurred.

Perhaps no area of evolution is more fraught with misconceptions than that of the evolutionary history of humans. Although biological evolution theory tells us that humans and modern apes evolved in present-day Africa from common primate ancestors some six million years ago (Smith \& Sullivan, 2007), a common misconception voiced by students is that humans evolved from monkeys, gorillas, or apes (Dagher \& BouJaoude, 1997; Lord \&Marino, 1993; Robbins \& Roy, 2007; Smith \& Sullivan, 2007). This study revealed 48.6\% $(n=482)$ of student participants adhere to this misconception (statement 21, "According to the theory of evolution, humans evolved from monkeys, gorillas, or apes.") as opposed to $42.3 \%(n=420)$ who did not. These results are comparable to a 1993 study of university students which found that $42.0 \%$ of students questioned stated humans evolved from monkeys (Lord \& Marino, 1993). For those students agreeing with statement $20(n=358), 34.4 \%$ $(n=123)$ disagreed with statement 21 indicating these individuals possess an accurate interpretation of both concepts. These 123 participants representing only $12.4 \%$ of all participants $(N=993)$ divulge a relatively high percentage of participants who possessed either one or both misconceptions related to this pair of statements. Of those participants agreeing with statement $20(n=358), 60.6 \%(n=217)$ also agreed with statement 21 . These participants apparently possess knowledge of the extent of evidence supporting the theory of evolution yet they hold the misconception that humans evolved from monkeys, gorillas, or apes through evolutionary processes. Similarly, of those participants who disagreed with statement $20(n=436), 51.1 \%(n=223)$ also disagreed with statement 21. While these individuals fail to recognize the abundance of evidence supporting evolution, they correctly assert that humans did not evolve from monkeys, gorillas, or apes. Finally, of those participants who disagreed with statement $20(n=420), 43.1 \%(n=181)$ agreed with statement 21 which indicates that these individuals claim both misconceptions associated with statements 20 and 21. Collectively, 74.2\% $(n=737)$ of participants held at least one misconception related to statements 20 and 21, resulting in a medium positive correlation of $r(983)=0.25, p<0.01$.

Statement 23 ("The majority of scientists favor evolution over other explanations for life") yielded $45.5 \%$ ( $n=$ 452) agreement among participants with $32.8 \%(n=326)$ in disagreement. Of those participants who agreed with statement $20(n=358), 59.5 \%(n=213)$ also agreed with statement 23 while $27.7 \%(n=99)$ disagreed, producing a medium positive correlation of $r(981)=0.30, p<0.01$ between statements 20 and 23. It is interesting that $10.0 \%$ of participants $(n=99)$ correctly indicate the existence of a large amount of evidence supporting evolution (statement 20) yet hold the misconception that the majority of scientists do not favor evolution over other explanations for life (statement 23). In addition, of those participants disagreeing with statement $20(n=$ 436), $42.0 \%(n=183)$ agreed with statement 23 . These participants contend that a large amount of evidence supporting evolution is lacking while at the same time believe the majority of scientists favor evolution over other explanations for life. These two contradictory concepts seem to indicate a lack of understanding of the process of science in these 183 individuals who represent $18.4 \%$ of participants.

Participants possessed a $42.7 \%$ mean rate of understanding coupled with a $39.7 \%$ mean misconception rate in response to the four Evidence Supporting Evolution statements while $17.6 \%$ of participants per statement were undecided or did not respond. Expressing no misconceptions related to the four statements were $12.9 \%(n=128)$ of participants while 35.0\% ( $n=348$ ) held one misconception; 35.5\% ( $n=352)$, two misconceptions; $14.2 \%(n=$ 114), three misconceptions; and $2.4 \%(n=24)$ held misconceptions related to each of the four statements. Collectively, $87.1 \%$ of participants $(n=865)$ held one or more misconceptions related to the four Evidence Supporting Evolution statements. 


\subsection{Summary}

Out of a possible maximum index score of 115 , student participants in this study $(N=993)$ earned a $70.34(S D=$ 7.04) BEL-MIS for the 23 statements. Out of a possible maximum index score of 25.0, the SSMT category of five statements $(1-5)$ produced a BEL-MIS of $15.61(S D=3.57)$ while the IE statements $(6-10)$ yielded a mean score of $15.61(S D=3.20)$, and the five ME statements (15 - 19), a 15.22 BEL-MIS $(S D=3.18)$. Out of a possible maximum index score of 20.0, the four NE category (statements 11 - 14) produced a BEL-MIS of 11.64 $(S D=2.26)$, while the four ESE category statements $(20-23)$ resulted in a BEL-MIS of $12.25(S D=2.65)$. Analysis of results revealed that student participants produced a mean $43.9 \%$ rate of understanding, $39.1 \%$ misconception rate, and a combined $17.0 \%$ undecided and nonresponse rate for the 23 BEL Survey statements. Participants' mean rates of understanding for the individual concept categories included: SSMT, 46.8\%; IE, 44.3\%; NE, 41.5\%; ME, 44.3\%; and ESE, 42.7\%, whereas the students' mean misconception rates per category were: SSMT, 35.2\%; IE, 37.5\%; NE, 43.8\%; ME, 39.4\%; and ESE, 39.7\%.

\subsection{Limitations of Study}

Like all survey-based research, the results reported in Table 3 have limitations. Even though incomplete student surveys and those showing obvious indications of noncompliance with instructions were eliminated from the study, students' efforts varied in completing the survey in an accurate manner. Moreover, the survey was administered by the students' Biology I teachers whose attitudes concerning biological evolution may have influenced the proper administration of the survey as well as their students' attitudes and responses. In addition, varying degrees of exposure to evolution concepts from sources such as parents, churches, media, textbooks, and previous as well as current science and nonscience courses, may have influenced students' responses.

Further limitations of this study involve two variables associated with the student participants which were significantly different $(p<0.05)$ from the population from which they originated. First, analysis revealed that the 42 public high schools from which the student participants originated were not representative of the collective 474 public high schools within the study area in terms of urban-centric classification, $\chi^{2}(3, N=42)=8.0, p=$ 0.046 . Specifically, only $2.4 \%$ of participants' high schools were classified as residing in cities as opposed to $7.2 \%$ of public high schools within the study region, while $26.2 \%$ of participants' high schools compared with $17.7 \%$ of those of the study region were town designated (see Table 2). As a result, student participants' BEL-MIS compared to the urban-centric classification of students' schools may not be truly representative of the study region. Second, a statistically significant difference was identified between the percentage of ethnicities in the student participant population (see Table 1) when compared to those of all public high school students within the study region, $\chi^{2}(44, N=997)=12.2, p=0.02$. As a result, student participants' BEL-MIS may not be truly representative of the study region in certain cases (IESNCES, 2010c). Specifically, Black non-Hispanic students were under-represented in the study (3.3\% as opposed to an expected $10.9 \%$ ) as were Hispanic students (5.6\% as opposed to an expected 11.2\%). Conversely, White, non-Hispanic students were over-represented in the study (71.8\% as opposed to an expected $56.4 \%$ ).

Despite these possible limitations, it is important to note that the study sample was large and students who did participate in this study were diverse and represented a variety of high schools (e.g., small, large, rural, city). In addition, the types and prevalence of biological evolution misconceptions held by these students were consistent with data reported in the literature (Beardsley, 2004; Bizzo, 1994; Clough \& Wood-Robinson, 1985; Creedy, 1993; Deadman \& Kelly 1978; Demastes et al., 1995; Evans, 2000; Geraedts \& Boersma, 2006; Halldén, 1988; Jiménez-Aleixandre, 1992; Jungwirth, 1975; Kampourakis \& Zogza, 2007, 2008, 2009; Lawson \& Thompson, 1988; Palmer, 1999; Pedersen \& Halldén, 1992; Prinou et al., 2008; Settlage, 1994; Shtulman, 2006; Spindler \& Doherty, 2009; Tamir \& Zohar, 1991).

\section{Conclusion}

"The single most important factor influencing learning is what the learner already knows" (Mintzes \& Wandersee, 1998: p. 81). This study explored what learners "already know" by investigating the prevalence of biological evolution-related misconceptions held by 993 Oklahoma public high school students prior to instruction in their initial high school biology course. Such misconceptions were prevalent within this population and the findings corroborate the literature that reports a strikingly high prevalence of biological evolution-related mis- 
conceptions in students at all levels, from elementary pupils to university science majors (Gregory, 2009), indicative of a pervasive problem in evolution education. In order for science educators to eliminate and replace their students' misconceptions with accurate science-based, biological evolution concepts, the following suggestions are offered.

First, as misconceptions may preclude an accurate understanding of biological evolution concepts, student misconceptions brought into the classroom must be identified. The National Research Council (NRC) reports that "research on students' conceptual misunderstanding of natural phenomena indicates that new concepts cannot be learned if alternative models that explain a phenomenon already exist in the learner's mind" (NRC Committee on Undergraduate Science Education, 1997: p. 28). Research involving student learning in the high school biology classroom suggests that there is a complicated synergism affecting the learning of evolution which includes the learner's prior conceptions related to evolution (Alters \& Nelson, 2002). In order for students to gain an accurate understanding of biological evolution concepts, students' misconceptions must be addressed within the classroom. If students' initial understanding is not engaged, they may fail to grasp the new concepts that are taught, or they may learn them for purposes of a test but revert to the preconceptions otherwise (Bransford et al., 2000). One means of identifying students' misconceptions is for the teacher to use an assessment tool (Wescott \& Cunningham, 2005). For example, the lead author administers the BEL Survey to students in his university nonmajor's biology course during the initial week of class and then adapts instruction based upon the results of the survey. Post-survey instruction typically includes a class discussion of the students' collective misconceptions. (See Cunningham \& Wescott, 2009 for a discussion of available assessment tools).

Second, sources of misconceptions must be identified. The scientific community regards evolution as a vital part of science education (NAS, 2008) yet evolutionary theory is one of the most commonly misunderstood areas in biology (Gregory, 2009). It is therefore imperative to identify sources of biological evolution misconceptions before one can effectively employ teaching practices to ameliorate misconceptions. Understanding students' perceptions of evolutionary theory requires an investigation into not only the sources of misconceptions concerning evolution (Modell et al., 2005; Novak, 2002; NRC, 1996; Wescott \& Cunningham, 2005) but the variety of factors that might influence the development of such perceptions (Hokayem \& BouJaoude, 2008). Sources from which these misconceptions arise are varied and can be complex (Modell et al., 2005). Such sources include: (a) from-experience misconceptions, (b) self-constructed misconceptions, (c) taught-and-learned misconceptions, (d) vernacular misconceptions, and (e) religious and myth-based misconceptions (Alters \& Nelson, 2002).

Once identified, teachers must address strategies for eliminating misconceptions that students bring into the classroom. Although a detailed description is beyond the scope of this paper, researchers have suggested several means of addressing student misconceptions about biological evolution in the classroom. These strategies include the constructivist approach of conceptual change (Alters \&Nelson, 2002; Cunningham \& Wescott, 2009; Lawson, 1994); historically rich curriculum with paired problem-solving instruction (Alters \& Nelson 2002; Cunningham \& Wescott, 2009; Jensen \& Finley, 1996); concept maps (Alters \& Nelson, 2002; Cunningham \& Wescott, 2009; Liu, 2004; Mintzes et al., 2001; Trowbridge \& Wandersee, 1994); and student-centered discussions (Alters \& Nelson, 2002).

Most importantly, science teachers, who welcome those students burdened with biological evolution misconceptions into their classrooms, must be well-grounded in evolutionary theory in order to identify such misconceptions and help replace them with accurate, science-based concepts. Unfortunately this is not always the case. A recent study involving the Biology I teachers of this current study's high school students revealed a disturbing $72.9 \%$ average rate of understanding of biological evolution-related concepts and a $23.0 \%$ misconception rate (combined 4.0\% undecided and nonresponse mean; Yates \& Marek, 2011). Disturbingly then, this present study's student participants, possessing a $43.9 \%$ rate of understanding coupled with an average misconception rate of $39.1 \%$, entered their initial high school biology course to be taught by teachers who produced a mean 23.0\% misconception rate on the same instrument. The question then begs: How many of these students' will complete their initial biology course with their misconceptions still intact? In addition, high school biology teachers must actually teach those biological evolution concepts as mandated by national and state curriculum standards and eliminate nonscience explanations within the science classroom (see Marek et al., 2006). Weld and McNew (1999) found that 33.0\% of Oklahoma public school life-science teachers in their study $(N=224)$ placed little or no emphasis on evolution while at the same time approximately $25.0 \%$ placed moderate or strong emphasis on creationism. 
Identification, elimination, and replacement of student misconceptions of biological evolution during high school science should begin in - and be a priority of - college and university science education programs. In particular, increased focus should be placed on preservice science teachers' evolution education. Research indicates that completion of an evolution course by preservice science teachers is a powerful predictor of advocacy of evolution, as well as classroom-time devoted to learning about evolution (Berkman et al., 2008; Donnelly \& Boone, 2007). Moreover teachers are more likely to integrate evolution concepts into their courses as a unifying theme (Berkman \& Plutzer, 2010). Such an emphasis is vitally important for identifying and reducing the number of biological evolution misconceptions that pervade high school biology courses. Many students will have the opportunity to reinforce previously learned biological evolution concepts and expand their knowledge in subsequent high school and college science courses. For some students, however, the only formal exposure to biological evolution in high school will be in their initial high school biology course. This initial biology course is the only high school science class for $21 \%$ to $25 \%$ of U.S. high school graduates (Berkman \& Plutzer, 2011) and the sole academic exposure to evolution for those who choose not to pursue a post-secondary education. Therefore, strategies must be in place to ensure that introductory biology teachers not only possess a thorough working knowledgeable of biological evolution but strategies for recognizing, addressing, and eliminating student-held misconception of evolution as well.

\section{Acknowledgements}

The authors thank those public high school teachers and students who participated in this research study.

\section{References}

Almquist, A. J., \& Cronin, J. E. (1988). Fact, Fancy, and Myth on Human Evolution. Current Anthropology, $29,520-522$. http://dx.doi.org/10.1086/203672

Alters, B. J., \& Alters, S. M. (2001). Defending Evolution: A Guide to the Creation/Evolution Controversy. Sudbury, MA: Jones and Bartlett.

Alters, B. J., \& Nelson, C. E. (2002). Perspective: Teaching Evolution in Higher Education. Evolution, 56, 1891-1901. http://dx.doi.org/10.1111/j.0014-3820.2002.tb00115.x

Anderson, D. L., Fisher, K. M., \& Norman, G. J. (2002). Development and Evaluation of the Conceptual Inventory of Natural Selection. Journal of Research in Science Teaching, 39, 952-978. http://dx.doi.org/10.1002/tea.10053

Beardsley, P. M. (2004). Middle School Student Learning in Evolution: Are Current Standards Achievable? American Biology Teacher, 66, 604, 606-607, 609-612. http://dx.doi.org/10.2307/4451757

Berkman, M. B., Pacheco, J. S., \& Plutzer, E. (2008). Evolution and Creationism in America’s Classrooms: A National Portrait. PLoS Biology, 6, e124. http://dx.doi.org/10.1371/journal.pbio.0060124

Berkman, M. B., \& Plutzer, E. (2010). Evolution, Creationism, and the Battle to Control America's Classrooms. Cambridge: Cambridge University Press. http://dx.doi.org/10.1017/CBO9780511760914

Berkman, M. B., \& Plutzer, E. (2011). Defeating Creationism in the Courtroom, but Not the Classroom. Science, 331, 404-405. http://dx.doi.org/10.1126/science.1198902

Berra, T. M. (1990). Evolution and the Myth of Creationism: A Basic Guide to the Facts in the Evolution Debate. Stanford, CA: Stanford University Press.

Bishop, B. A., \& Anderson, C. W. (1986). Evolution by Natural Selection: A Teaching Module. Occasional Paper 91, East Lansing, MI: Institute for Research on Teaching, Michigan State University, ERIC No. ED272383.

Bishop, B. A., \& Anderson, C. W. (1990). Student Conceptions of Natural Selection and Its Role in Evolution. Journal of Research in Science Teaching, 27, 415-427. http://dx.doi.org/10.1002/tea.3660270503

Bizzo, N. M. V. (1994). From Down House Landlord to Brazilian High School Students: What Has Happened to Evolutionary Knowledge on the Way? Journal of Research in Science Teaching, 31, 537-556.

http://dx.doi.org/10.1002/tea.3660310508

Bransford, J. D., Brown, A. L., \& Cocking, R. R. (Eds.) (2000). How People Learn. Washington DC: National Academy Press.

Brem, S. K., Ranney, M., \& Schindel, J. (2002). Perceived Consequences of Evolution: College Students Perceive Negative Personal and Social Impact in Evolutionary Theory. Science Education, 87, 181-206. http://dx.doi.org/10.1002/sce.10105

Brumby, M. (1979). Problems in Learning the Concept of Natural Selection. Journal of Biological Education, 13, 119-122. http://dx.doi.org/10.1080/00219266.1979.9654240 
Brumby, M. (1984). Misconceptions about the Concept of Natural Selection by Medical Biology Students. Science Education, 68, 493-503. http://dx.doi.org/10.1002/sce.3730680412

Chan, K. S. (1998). A Case Study of Physicist’s Conceptions about the Theory of Evolution. Annual Meeting of the National Association of Research and Science Teaching, San Diego, April 1998.

Chinsamy, A., \& Plagányi, È. (2007). Accepting Evolution. Evolution, 62, 248-254. http://dx.doi.org/10.1111/j.1558-5646.2007.00276.x

Clough, E. E., \& Wood-Robinson, C. (1985). How Secondary Students Interpret Instances of Biological Adaptation. Journal of Biological Education, 19, 125-130. http://dx.doi.org/10.1080/00219266.1985.9654708

Creedy, L. J. (1993). Student Understandings of Natural Selection. Research in Science Education, 23, 34-41. http://dx.doi.org/10.1007/BF02357042

Cunningham, D. L., \& Wescott, D. J. (2009). Still More “Fancy” and "Myth” than "Fact” in Students' Conceptions of Evolution. Evolution: Education and Outreach, 2, 505-517. http://dx.doi.org/10.1007/s12052-009-0123-6

Dagher, Z. R., \& BouJaoude, S. (1997). Scientific Views and Religious Beliefs of College Students: The Case of Biological Evolution. Journal of Research in Science Teaching, 34, 429-445. http://dx.doi.org/10.1002/(SICI)1098-2736(199705)34:5<429::AID-TEA2>3.0.CO;2-S

Dagher, Z. R., \& BouJaoude, S. (2005). Students’ Perceptions of the Nature of Evolutionary Theory. Science Education, 89, 378-391. http://dx.doi.org/10.1002/sce.20054

Darwin, C. (1872). On the Origin of Species by Means of Natural Selection (6th ed.). London: Murray. http://darwin-online.org.uk/content/frameset?itemID=F391\&viewtype=text\&pageseq=1

Deadman, J. A., \& Kelly, P. J. (1978). What Do Secondary School Boys Understand about Evolution and Heredity before They Are Taught the Topics? Journal of Biological Education, 12, 7-15. http://dx.doi.org/10.1080/00219266.1978.9654169

Demastes, S. S., Settlage, J., \& Good, R. G. (1995). Students’ Conceptions of Natural Selection and Its Role in Evolution: Cases of Replication and Comparison. Journal of Research in Science Teaching, 32, 535-550. http://dx.doi.org/10.1002/tea.3660320509

Dobzhansky, T. (Ed.) (1973). Nothing in Biology Makes Sense Except in the Light of Evolution. American Biology Teacher, 35, 125-129. http://dx.doi.org/10.2307/4444260

Donnelly, L. A., \& Boone, W. J. (2007). Biology Teachers' Attitudes Toward and Use of Indiana's Evolution Standards. Journal of Research in Science Teaching, 44, 236-257. http://dx.doi.org/10.1002/tea.20150

Duit, R., \&Treagust, D. F. (2003). Conceptual Change: A Powerful Framework for Improving Science Teaching and Learning. International Journal of Science Education, 25, 671-688. http://dx.doi.org/10.1080/09500690305016

Evans, E. M. (2000). The Emergence of Beliefs about the Origins of Species in School-Age Children. Merrill-Palmer Quarterly, 46, 221-254.

Evans, E. M. (2001). Cognitive and Contextual Factors in the Emergence of Diverse Belief Systems: Creation versus Evolution. Cognitive Psychology, 42, 217-266. http://dx.doi.org/10.1006/cogp.2001.0749

Evans, E. M., Spiegel, A. N., Gram, W., Frazier, B. N., Tare, M., Thompson, S. et al. (2010). A Conceptual Guide to Natural History Museum Visitors’ Understanding of Evolution. Journal of Research in Science Teaching, 47, 326-353.

Ferrari, M., \& Chi, M. T. H. (1998). The Nature of Naïve Explanations of Natural Selection. International Journal of Science Education, 20, 1231-1256. http://dx.doi.org/10.1080/0950069980201005

Futuyma, D. J. (1995). Science on Trial: The Case for Evolution. Sunderland, MA: Sinauer Associates.

Futuyma, D. J. (1998). Evolutionary Biology (3rd ed.). Sunderland, MA: Sinauer Associates.

Geraedts, C. L., \& Boersma, K. T. (2006). Reinventing Natural Selection. International Journal of Science Education, 28, 843-870. http://dx.doi.org/10.1080/09500690500404722

Greene Jr., E. D. (1990). The Logic of University Students’ Misunderstanding of Natural Selection. Journal of Research in Science Teaching, 27, 875-885. http://dx.doi.org/10.1002/tea.3660270907

Gregory, T. R. (2009). Understanding Natural Selection: Essential Concepts and Common Misconceptions. Evolution: Education and Outreach, 2, 156-175. http://dx.doi.org/10.1007/s12052-009-0128-1

Guralnick, D. B. (Ed.) (1980). New World Dictionary of the American Language (2nd College ed.). New York: Simon and Schuster.

Halldén, O. (1988). The Evolution of the Species: Pupil Perspectives and School Perspectives. International Journal of Science Education, 10, 541-552. http://dx.doi.org/10.1080/0950069880100507

Hokayem, H., \& BouJaoude, S. (2008). College Students' Perceptions of the Theory of Evolution. Journal of Research in Science Teaching, 45, 395-419. http://dx.doi.org/10.1002/tea.20233 
Institute of Education Sciences National Center for Educational Statistics (2010a). Digest of Education Statistics Appendix b: Definitions. http://nces.ed.gov/pubs2011/2011015.pdf

Institute of Education Sciences National Center for Educational Statistics (2010b). Common Core of Data. http://nces.ed.gov/ccd/rural_locales.asp

Institute of Education Sciences National Center for Educational Statistics (2010c). State Education Data Profiles. http://nces.ed.gov/programs/stateprofiles/sresult.asp?mode=full\&displaycat=1\&s1=40

Isaak, M. (2003). Five Major Misconceptions about Evolution. The TalkOrigins Archive. http://talkorigins.org/faqs/faq-misconceptions.html

Jensen, M. S., \& Finley, F. N. (1995). Teaching Evolution Using Historical Arguments in a Conceptual Change Strategy. Science Education, 79, 147-166. http://dx.doi.org/10.1002/sce.3730790203

Jensen, M. S., \& Finley, F. N. (1996). Changes in Students' Understanding of Evolution Resulting from Different Curricular and Instructional Strategies. Journal of Research in Science Teaching, 33, 879-900.

http://dx.doi.org/10.1002/(SICI)1098-2736(199610)33:8<879::AID-TEA4>3.0.CO;2-T

Jiménez-Aleixandre, M. P. (1992). Thinking about Theories or Thinking with Theories? A Classroom Study with Natural Selection. International Journal of Science Education, 14, 51-61. http://dx.doi.org/10.1080/0950069920140106

Jiménez-Aleixandre, M. P., \& Fernández-Pérez, J. (1987). Selection or Adjustment? Explanations of University Biology Students for Natural Selection Problems. In J. D. Novak (Ed.), Proceedings of the Second International Seminar on Misconceptions and Educational Strategies in Science and Mathematics (Vol. 2, pp. 224-232). Ithaca, NY: Department of Education, Cornell University.

Jungwirth, E. (1975). The Problem of Teleology in Biology as a Problem of Biology Teacher Education. Journal of Biological Education, 9, 243-246. http://dx.doi.org/10.1080/00219266.1975.9654037

Kampourakis, K., \& Zogza, V. (2007). Students’ Preconceptions about Evolution: How Accurate Is the Characterization as "Lamarckian” When Considering the History of Evolutionary Thought? Science \& Education, 16, 393-422. http://dx.doi.org/10.1007/s11191-006-9019-9

Kampourakis, K., \& Zogza, V. (2008). Students' Intuitive Explanations of the Causes of Homologies and Adaptations. Science \& Education, 17, 27-47. http://dx.doi.org/10.1007/s11191-007-9075-9

Kampourakis, K., \& Zogza, V. (2009). Preliminary Evolutionary Explanations: A Basic Framework for Conceptual Change and Explanatory Coherence in Evolution. Science \& Education, 18, 1313-1340.

http://dx.doi.org/10.1007/s11191-008-9171-5

Kelemen, D., \& Rosset, E. (2009). The Human Function Compunction: Teleological Explanation in Adults. Cognition, 111, 138-143. http://dx.doi.org/10.1016/j.cognition.2009.01.001

Lawson, A. E. (1994). Research on the Acquisition of Science Knowledge: Epistemological Foundation of Cognition. In D. I. Gabel (Ed.), Handbook of Research on Science Teaching and Learning (pp. 131-176). New York: Macmillan.

Lawson, A. E., \& Thompson, L. D. (1988). Formal Reasoning Ability and Misconceptions Concerning Genetics and Natural Selection. Journal of Research in Science Teaching, 25, 733-746. http://dx.doi.org/10.1002/tea.3660250904

Liu, X. (2004). Using Concept Mapping for Assessing and Promoting Relational Conceptual Change in Science. Science Education, 88, 373-396. http://dx.doi.org/10.1002/sce.10127

Lord, T., \& Marino, S. (1993). How University Students View the Theory of Evolution. Journal of College Science Teaching, 22, 353-357.

Losh, S. C., Travani, C. M., Njoroge, R., Wilke, R., \& Mcauley, M. (2003). What Does Education Really Do? Educational Dimensions and Pseudoscience Support in American General Public, 1979-2001. Skeptical Inquirer, 27, 30-36.

Marek, E. A., Carrington, M., Everson, D. P., Johnson, A., \& Mescolotto, L. M. (2006). Why We Shouldn’t 'Teach the Controversy' in Science. Forum on Public Policy: Forum on Public Policy Online, 3, 7 p.

Mayr, E. (1982). The Growth of Biological Thought: Diversity, Evolution and Inheritance. Cambridge: Belknap Press of Harvard.

Mayr, E. (2001). What Evolution Is. New York: Basic Books.

Mazur, A. (2004). Believers and Disbelievers in Evolution. Politics and the Life Sciences, 23, 55-61. http://dx.doi.org/10.2990/1471-5457(2004)23[55:BADIE]2.0.CO;2

McComas, W. F. (2006). Investigating Evolutionary Biology in the Laboratory. Dubuque, IA: Kendall/Hunt.

Mead, L. S., \& Scott, E. C. (2010a). Problem Concepts in Evolution Part I: Purpose and Design. Evolution: Education and Outreach, 3, 78-81. http://dx.doi.org/10.1007/s12052-010-0210-8

Mead, L. S., \& Scott, E. C. (2010b). Problem Concepts in Evolution Part II: Cause and Chance. Evolution: Education and Outreach, 3, 261-264. http://dx.doi.org/10.1007/s12052-010-0231-3 
Meir, E., Perry, J., Herron, J. C., \& Kingsolver, J. (2007). College Students’ Misconceptions about Evolutionary Trees. American Biology Teacher, 69, e71-e76. http://dx.doi.org/10.1662/0002-7685(2007)69[71:CSMAET]2.0.CO;2

Mintzes, J. J., \& Wandersee, J. H. (1998). Research in Science Teaching and Learning: A Human Constructivist View. In J. J. Mintzes, J. H. Wandersee, \& J. D. Novak (Eds.), Teaching Science for Understanding: A Human Constructivist View (pp. 59-92). San Diego, CA: Academic Press.

Mintzes, J. J., Wandersee, J. H., \& Novak, J. D. (2001). Assessing Understanding in Biology. Journal of Biological Education, 35, 118-124. http://dx.doi.org/10.1080/00219266.2001.9655759

Modell, H., Michael, J., \& Wenderoth, M. P. (2005). Helping the Learner to Learn: The Role of Uncovering Misconceptions. American Biology Teacher, 67, 20-26. http://dx.doi.org/10.1662/0002-7685(2005)067[0020:HTLTLT]2.0.CO;2

Morrison, J. A., \& Lederman, N. G. (2003). Science Teachers’ Diagnosis and Understanding of Students’ Preconceptions. Science Education, 87, 849-867. http://dx.doi.org/10.1002/sce.10092

National Academy of Sciences (1998). Teaching about Evolution and the Nature of Science. Washington DC: National Academy Press.

National Academies of Science (NAS) (2008). Science, Evolution, and Creationism. Washington DC: The National Academies Press.

National Research Council (NRC) (1996). National Science Education Standards. Washington DC: National Academy Press.

National Research Council Committee on Undergraduate Science Education (1997). Science Teaching Reconsidered: A Handbook. Washington DC: National Academy Press.

Nehm, R. H., Poole, T. M., Lyford, M. E., Hoskins, S. G., Carruth, L., Ewers, B. E. et al. (2009). Does the Segregation of Evolution in Biology Textbooks and Introductory Courses Reinforce Students' Faulty Mental Models of Biology and Evolution? Evolution: Education and Outreach, 2, 527-532. http://dx.doi.org/10.1007/s12052-008-0100-5

Nehm, R. H., \& Reilly, L. (2007). Biology Majors’ Knowledge and Misconceptions of Natural Selection. BioScience, 57, 263-272. http://dx.doi.org/10.1641/B570311

Nehm, R. H., \& Schonfeld, I. S. (2007). Does Increasing Biology Teacher Knowledge of Evolution and the Nature of Science Lead to Greater Preference for the Teaching of Evolution in Schools? Journal of Science Teacher Education, 18, 699-723. http://dx.doi.org/10.1007/s10972-007-9062-7

Nelson, C. E. (2008). Teaching Evolution (and All of Biology) More Effectively: Strategies for Engagement, Critical Reasoning, and Confronting Misconceptions. In Evolution vs. Creationism in the Classroom: Evolving Student Attitudes Symposium (pp. 213-225). New York: Oxford University Press.

Novak, J. D. (2002). Meaningful Learning: The Essential Factor for Conceptual Change in Limited or Inappropriate Propositional Hierarchies Leading to Empowerment of Learners. Science Education, 86, 548-571. http://dx.doi.org/10.1002/sce.10032

Oklahoma State Department of Education (2009a). 2009-2010 Oklahoma Directory of Education. Oklahoma City, OK: Oklahoma State Department of Education.

Oklahoma State Department of Education (2009b). Graduation—Oklahoma Requirements for High School. http://ok.gov/sde/sites/ok.gov.sde/files/ACE-Checklist.pdf

Oklahoma State Department of Education (2009c). Priority Academic Student Skills. http://ok.gov/sde/oklahoma-c3-priority-academic-student-skills

Palmer, D. H. (1999). Exploring the Link between Students' Scientific and Nonscientific Conceptions. Science Education, 83, 639-653. http://dx.doi.org/10.1002/(SICI)1098-237X(199911)83:6<639::AID-SCE1>3.0.CO;2-O

Passmore, C., \& Stewart, J. (2002). A Modeling Approach to Teaching Evolutionary Biology in High Schools. Journal of Research in Science Teaching, 39, 185-204. http://dx.doi.org/10.1002/tea.10020

Paz-y-Mińo, C. G., \& Espinosa, A. (2009). Assessment of Biology Majors’ versus Nonmajors’ Views on Evolution, Creationism, and Intelligent Design. Evolution: Education and Outreach, 2, 75-83. http://dx.doi.org/10.1007/s12052-008-0096-x

Pedersen, S., \& Halldén, O. (1992). Intuitive Ideas and Scientific Explanations as Parts of Students’ Developing Understanding of Biology: The Case of Evolution. European Journal of Psychology of Education, 9, 127-137. http://dx.doi.org/10.1007/BF03173548

Petto, A. J., \& Mead, L. S. (2008). Misconceptions about the Evolution of Complexity. Evolution: Education and Outreach, 1, 505-508. http://dx.doi.org/10.1007/s12052-008-0082-3

Prinou, L., Halkia, L., \& Skordoulis, C. (2008). What Conceptions Do Greek School Students Form about Biological Evolution? Evolution: Education and Outreach, 1, 312-317. http://dx.doi.org/10.1007/s12052-008-0051-X

Ridley, M. (1996). Evolution (2nd ed.). Cambridge: Blackwell Scientific. 
Robbins, J. R., \& Roy, P. (2007). The Natural Selection: Indentifying and Correcting Non-Science Student Preconceptions through an Inquiry-Based, Critical Approach to Evolution. American Biology Teacher, 69, 460-466. http://dx.doi.org/10.1662/0002-7685(2007)69[460:TNSICN]2.0.CO;2

Rutledge, M. L., \& Warden, M. A. (2002). High School Biology Teachers’ Knowledge Structure, Acceptance, and Teaching of Evolution. American Biology Teacher, 64, 21-28. http://dx.doi.org/10.1662/0002-7685(2002)064[0021:HSBTKS]2.0.CO;2

Sadler, T. D. (2005). Evolutionary Theory as a Guide to Socioscientific Decision Making. Journal of Biological Education, 39, 68-72. http://dx.doi.org/10.1080/00219266.2005.9655964

Samarapungavan, A., \& Wiers, R. W. (1997). Children’s Thoughts on the Origin of Species: A Study of Explanatory Coherence. Cognitive Science, 21, 147-177. http://dx.doi.org/10.1207/s15516709cog2102_2

Scott, E. C. (2004). Evolution vs. Creationism: An Introduction. Los Angeles, CA: University of California.

Settlage, J. (1994). Conceptions of Natural Selection: A Snapshot of the Sense-Making Process. Journal of Research in Science Teaching, 31, 449-457. http://dx.doi.org/10.1002/tea.3660310503

Shermer, M. (2006). Why Darwin Matters. New York: Henry Holt and Company.

Shtulman, A. (2006). Qualitative Differences between Naïve and Scientific Theories of Evolution. Cognitive Psychology, 52, 170-194. http://dx.doi.org/10.1016/j.cogpsych.2005.10.001

Sinatra, G. M., Brem, S. K., \& Evans, E. M. (2008). Changing Minds? Implications of Conceptual Change for Teaching and Learning about Biological Evolution. Evolution: Education and Outreach, 1, 189-195.

http://dx.doi.org/10.1007/s12052-008-0037-8

Smith, C. M., \& Sullivan, C. (2007). The Top 10 Myths about Evolution. Amherst, NY: Prometheus Books.

Southerland, S. A., Abrams, E., Cummins, C. L., \& Anzelmo, J. (2001). Understanding Students’ Explanations of Biological Phenomena: Conceptual Frameworks or P-Prims? Science Education, 85, 328-348. http://dx.doi.org/10.1002/sce.1013

Spindler, L. H., \& Doherty, J. H. (2009). Assessment of the Teaching of Evolution by Natural Selection through a Hands-On Simulation. Teaching Issues and Experiments in Ecology, 6, 1-20.

Stern, L., \& Ben-Akiva, I. (2007). Tails’ Inheritance: Challenging Secondary School Students' Ideas about the Inheritance of Acquired Traits. American Biology Teacher, 69, 76-79. http://dx.doi.org/10.1662/0002-7685(2007)69[76:TICSSS]2.0.CO;2

Sundberg, M. D., \& Dini, M. L. (1993). Science Majors vs. Nonmajors: Is There a Difference? Journal of College Science Teaching, 22, 299-304.

Tamir, P., \& Zohar, A. (1991). Anthropomorphism and Teleology in Reasoning about Biological Phenomena. Science Education, 75, 57-67. http://dx.doi.org/10.1002/sce.3730750106

Trowbridge, J. E., \& Wandersee, J. H. (1994). Identifying Critical Junctures in Learning in a College Course on Evolution. Journal of Research in Science Teaching, 31, 459-473. http://dx.doi.org/10.1002/tea.3660310504

U.S. Census Bureau (2009). American Community Survey. http://www.Okcommerce.gov/Data-And-Research/Downloads/2009-American-Community-Survey-1-Year-Data

U.S. Census Bureau (2010). Regions and Divisions. http://www.census.gov/econ/census/help/geography/regions_and_divisions.html

Wandersee, J. H., Mintzes, J. J., \& Novak, J. D. (1994). Research in Alternative Conceptions in Science: Part II Learning. In D. L. Gabel (Ed.), Handbook of Research on Science Teaching and Learning (pp. 177-210). New York: Macmillan.

Weld, J., \& McNew, J. C. (1999). Attitudes toward Evolution. Science Teacher, 66, 27-31.

Wescott, D. J., \& Cunningham, D. L. (2005). Recognizing Student Misconceptions about Science and Evolution. Mountain Rise, 2, 1-8.

Wilson, J. A. (2001). Pseudoscientific Beliefs among College Students. Reports of the National Center for Science Education, 21, 9-13.

Yates, T., \& Marek, E. A. (2011). A Regional Study of the Types and Prevalence of Biological Evolution-Related Misconceptions Held by Public Secondary School Biology Teachers. International Conference of the National Association for Researchers in Science Teaching, Orlando, 3-6 April 2011. 